\title{
Impact of partial steps and momentum advection schemes in a global ocean circulation model at eddy permitting resolution.
}

\author{
Barnier BERNARD ${ }^{1, *}$, Gurvan MADEC ${ }^{2}$, Thierry PENDUFF ${ }^{1}$, Jean-Marc MOLINES ${ }^{1}$, \\ Anne-Marie TREGUIER ${ }^{3}$, Julien LE SOMMER ${ }^{1}$, Aike BECKMANN ${ }^{4}$, Arne BIASTOCH ${ }^{5}$, \\ Claus BÖNING ${ }^{5}$, Joachim DENGG ${ }^{5}$, Corine DERVAL ${ }^{6}$, Edmée DURAND ${ }^{6}$, Sergei \\ GULEV $^{7}$, Elizabeth REMY ${ }^{6}$, ClaudeTALANDIER ${ }^{2}$, Sébastien THEETTEN ${ }^{3}$, Mathew \\ MALTRUD $^{8}$, Julie MCCLEAN ${ }^{9}$, Beverly DE CUEVAS ${ }^{10}$
}

\footnotetext{
${ }^{1}$ Laboratoire des Ecoulements Géophysiques et Industriels, Grenoble, France

${ }^{2}$ Laboratoire d'Océanographie Dynamique et de Climatologie, Paris, France

${ }^{3}$ Laboratoire de Physique des Océans, Ifremer Centre de Brest, Plouzané, France

${ }^{4}$ Department of Physical Sciences, Division of Geophysics, University of Helsinki, Helsinki, Finland

5 IfM-GEOMAR, Leibniz-Institut für Meereswissenschaften an der Universität Kiel, Kiel, Germany

${ }^{6}$ MERCATOR-Ocean, Toulouse, France

7 Shirshov Institut of Oceanography, Russian Academy of Science, Moscow, Russia

${ }^{8}$ Fluid Dynamics Group, Los Alamos National Laboratory, Los Alamos, USA

${ }^{9}$ Scripps Institution of Oceanography, UCSD, LA Jolla,USA

${ }^{10}$ National Oceanography Centre, Southampton, UK
}

\section{*: Corresponding author : Barnier BERNARD - Email: bernard.barnier@hmg.inpg.fr}

\begin{abstract}
:
Series of sensitivity tests have been performed with a z-coordinate, global eddy permitting $\left(1 / 4^{\circ}\right)$ ocean/sea-ice model (the ORCA-R025 model configuration developed for the DRAKKAR project), to carefully evaluate theim pact of recent state of the art numerical schemes on model solutions. The combination of an energy-enstrophy conserving scheme (EEN) for momentum advection with a partial step (PS) representation of the bottom topography yields significant improvements in the mean circulation. Well known biases in the representation of western boundary currents, such as in the Atlantic the detachment of the Gulf Stream, the path of the North Atlantic Current, the location of the Confluence and the strength of the Zapiola Eddy in the south Atlantic, are partly corrected.

Similar improvements are found in the Pacific, Indian and Southern Oceans, and characteristics of the mean flow are generally much closer to observations. Comparisons with other state of the art models show that the ORCA -R025 configuration generally performs better at similar resolution. In addition, the model solution is often comparable to solutions obtained at $1 / 6^{\circ}$ or $1 / 10^{\circ}$ resolution in some aspects concerning mean flow patterns and distribution of eddy kinetic energy. Although the reasons for these improvements are not analysed in detail in this paper, evidence is shown that the combination of EEN with PS reduces numerical noise near the bottom which is likely to affect currenttopography interactions in a systematic way. We conclude that significant corrections of the mean biases presently seen in general circulation model solutions at eddy permitting resolution can still be expected from the development of numerical methods which represent an alternative to increasing resolution.
\end{abstract}

Keywords: Global ocean; Eddy-permitting ocean model; Momentum advection scheme; Partial step topography; Eddy/topography interactions 


\section{INTRODUCTION}

In a special issue honouring the memory of Christian Le Provost, it is fitting for many of us who collaborated with him, sometimes very closely and for almost twenty years, to place the work presented here in relation to scientific issues he stood by. Christian Le Provost's first involvement in the field of ocean circulation modelling was motivated by the World Ocean Circulation Experiment (WOCE) in the mid 80's. His intuition was that among all processes which have a crucial influence in shaping the mean circulation, two of particular importance were overlooked: the mesoscale eddies and the constraint of the bottom topography. His early work therefore concentrated on process studies searching for a better understanding and modelling of the generation of eddies in the presence of topography (Verron and Le Provost 1985, Verron, Le Provost and Holland, 1987) and the interaction of turbulent large scale flows with topography (Barnier and Le Provost, 1993). He also emphasised the crucial importance of numerics on the realism of model solutions (Blayo and Le Provost, 1993). Christian convinced himself and his group that accurate modelling of the effect of bottom topography on ocean nonlinear flows is a key to achieve realistic simulations of the global ocean circulation. This belief underlay the model intercomparison DYNAMO project (DYNAMO Group, 1997) which he designed with Jürgen Willebrand (Willebrand et al., 1991).

Building and running ocean models able to simulate the world ocean circulation with great realism require a great variety of scientific skills. Christian Le Provost was aware that gathering all the necessary skills within a single research team as the one he was leading would be difficult. Consequently, he always favoured community experiments, in the spirit of the Community Model Experiment (CME) carried out under WOCE (Bryan and Holland, 1989, Böning and Bryan, 1996). This concept of community projects, which Christian shared with Jürgen Willebrand, Bill Holland and others, was at the core of the DYNAMO project. It has been at the origin of the French CLIPPER project (Treguier et al., 1999), and is the basis of the international DRAKKAR project which is briefly presented here. These are projects in which Christian Le Provost actively participated.

The present paper is strongly inspired by the issues mentioned above. It presents recent advances in modelling the general ocean circulation at eddy-permitting resolution achieved in the framework of the European modelling project DRAKKAR. Indeed, eddy-permitting models are still worth exploring and enhancing, despite the existing higher resolution models, since they will be the target resolution of the next generation of climate models. Improvements presented here mainly concern the representation of ocean flows in regions where the circulation is dominated 
by non- linearities and is strongly constrained by bottom topography. These results were obtained by using a new numerical treatment of the non-linear advection term in momentum equations, and a partial step representation of the bottom topography.

The paper is organised as follows. Section 2 describes the eddy permitting, global, $1 / 4^{\circ}$ model configuration implemented by the project, ORCA-R025. It also presents the mean circulation produced by ORCA-R025 under a climatological atmospheric forcing. Section 3 evaluates the impact of new numerical choices regarding bottom topography and momentum, in direct relation with Christian Le Provost early intuition, by comparison of ORCA-R025 simulations with observations and other state of the art model simulations at equivalent or higher resolution. The last section is a conclusion which identifies key issues where problems remain and ways of improvements.

\section{GLOBAL $1 / 4^{\circ}$ DRAKKAR CONFIGURATION ORCA-R025}

\subsection{DRAKKAR project}

During the last decade, scientists participating in the DRAKKAR ${ }^{1}$ project fostered co-operative activities within the European project DYNAMO (Dynamics of North Atlantic Models, DYNAMO Group - 1997), and between their respective national projects, CLIPPER in France (Treguier et al., 1999) and FLAME (Family of Linked Atlantic models) in Germany (Böning et al., 2003). The challenge of developing realistic global ocean models suited for a wide range of applications will be better met with an effective integration and co-ordination of activities and complementary expertises of the groups. This yielded the DRAKKAR concept, a European modelling project which provides the framework for joint and co-ordinated modelling studies between research groups in France, Germany, Russia and Finland.

One primary concern of the project is related to the circulation and variability in the North Atlantic Ocean as driven by the atmospheric forcing, by interactions between processes of different scales, by exchanges between basins and regional circulation features (including the Nordic Seas), and by the influence of the world ocean circulation (including the Arctic and Southern Oceans and the Agulhas retroflection region). To achieve these scientific objectives, DRAKKAR is carrying out co-ordinated realistic simulations of the ocean circulation at regional

\footnotetext{
${ }^{1}$ http://www.ifremer.fr/lpo/drakkar
} 
and global scales, with pertinent atmospheric forcing and resolutions high enough to insure physical consistency over the range of scales which are dynamically important (i.e. from eddy to global, from day to decade).

As first objective, the project has built a hierarchy of numerical model configurations, from global to regional scale, each based on the $\mathrm{NEMO}^{2}$ modelling system which presently includes the latest version of the primitive equation, free surface (Roullet and Madec, 2000), ocean circulation code OPA9 (Madec et al., 1998) coupled to the multi-layered sea-ice code LIM2 (Fichefet et al, 1997). This hierarchy of models includes the ORCA-R025 configuration, an eddy-permitting, global ocean/sea-ice configuration with a resolution of $1 / 4^{\circ}$ described below.

\subsection{GLOBAL $1 / 4^{\circ}$ DRAKKAR CONFIGURATION ORCA-R025}

\section{ORCA Grid common to all DRAKKAR configurations}

In the OPA numerical code (Madec et al., 1998), the primitive equations are discretised on a Cgrid centered at tracer points. A family of tri-polar grids, ORCA grids, has been developed by Madec (Personal communication) for global models (see Timmermann et al., 2005, for an application of the ORCA grid at $2^{\circ}$ resolution). The geographical south pole is conserved, and from $80^{\circ} \mathrm{S}$ to $20^{\circ} \mathrm{N}$, the grid is a regular Mercator-grid (isotropic, getting finer at high latitude as the cosine of latitude). Following Murray's (1995) idea, the singularity of the North Pole is treated by changing the coordinate system using two poles, one in Canada and the other in Asia. Starting at $20^{\circ} \mathrm{N}$, latitude circles of the Mercator-grid are progressively distorted into ellipses, the great axes of which are oriented along a line joining the two poles of the northern hemisphere. The grid is computed following the semi-analytical method of Madec and Imbard (1996). The deformation of the grid is such that it remains quasi-isotropic, and is quasi-uniform in the Arctic. Since the resolution of the grid is variable, the resolution of an ORCA grid is referred to the latitude of the equator, where it is the coarsest. This family of grid is used for all DRAKKAR configurations, including the regional ones (North Atlantic and Nordic Seas).

\footnotetext{
${ }^{2}$ NEMO: Nucleus for European Models of the Ocean
} 


\section{Model grid, bathymetry and initial conditions}

ORCA-R025 is a global configuration of NEMO implemented on an ORCA grid at $1 / 4^{\circ}$ resolution. Grid, masking and initial conditions are inherited from the global configuration of the operational oceanography centre MERCATOR-Ocean ${ }^{3}$ (Remy et al., personal communication). This configuration has $1442 \times 1021$ grid points and uses 46 vertical levels. Vertical grid spacing is finer near the surface $(6 \mathrm{~m})$ and increases with depth to $250 \mathrm{~m}$ at the bottom. The maximum depth in the model is $5844 \mathrm{~m}$. The effective resolution which gets finer with increasing latitudes is $\sim 27.75 \mathrm{~km}$ at the equator, $\sim 13.8 \mathrm{~km}$ at $60^{\circ} \mathrm{S}$ or $60^{\circ} \mathrm{N}$. It gets to $\sim 7 \mathrm{~km}$ in the Weddell and Ross Seas and $\sim 10 \mathrm{~km}$ in the Arctic.

The bathymetry is derived from the 2-minute resolution Etopo2 bathymetry file of NGDC (National Geophysical Data Center), which is a combination of the satellite-based bathymetry (Smith and Sandwell (1997) and IBCAO in the Arctic (Jakobsson et al., 2000). It has been merged with the BEDMAP data (Lythe and Vaughan, 2001) beyond $72^{\circ} \mathrm{S}$ in the Antarctic. The interpolation onto the model grid has been carried out by taking all the Etopo 2 grid points falling into an ORCA025 grid box, and taking the median of those points. This produces a smoothing of the sub-grid scale topography. Penduff et al (2002) showed that topographic smoothing has a strong influence on the model's circulation. We believe that topography should not vary too much at the grid scale to avoid numerical noise. For this reason, we have applied an additional smoothing (two passes of a uniform shapiro filter). Hand editing has been performed in a few key areas. Initial conditions for temperature and salinity are derived from the Levitus (1998) data set for the middle and low latitudes. For high latitudes we chose the PHC2.1 climatology (Steele et al., 2001) and for the Mediterranean Sea the Medatlas climatology (Jourdan et al, 1998).

\section{Numerical characteristics}

A purpose of developing the NEMO code is to improve model physics and numerical algorithms. Perhaps the most significant problem in eddy-permitting z-coordinate ocean models is the misrepresentation of flow-topography interactions (Penduff et al., 2005). The previous version of OPA (OPA 8.1, Madec et al., 1998) represented the topography as staircases whose steps have the size of the model vertical levels: this is the "full step" (FS) topography, which approximates the true ocean depth to the closest model level. By making the depth of the bottom cell variable and adjustable to the real depth of the ocean, it is possible to better represent small topographic

\footnotetext{
${ }^{3}$ MERCATOR-Ocean: httm://www.mercator-ocean.fr
} 
slopes: this is the "partial step" (PS) topography, first introduced by Adcroft et al. (1997) and also named partial cells in the literature (Pacanowski and Gnanadesikan, 1998). This PS representation of the topography is now available in NEMO.

In OPA, the momentum equations are expressed in their vector invariant formulation (i.e. as a relative vorticity term plus a gradient of kinetic energy and a vertical advection) instead of the flux form (i.e. divergence of momentum fluxes plus a metric term) used in most ocean general circulation models. At this point, several options are possible to discretise the total (relative + planetary) vorticity term. Two distinct schemes are used in the present paper. One is the standard scheme used in the former versions of OPA (referred to as the ENS scheme) and has the property to conserve enstrophy (Sadourny, 1975) in flows with no mass flux divergence. The other, which is newly available in NEMO, is an adaptation of the scheme of Arakawa and Lamb (1981) to the primitive equations. Referred to as the EEN scheme, it conserves total energy for general flow and potential enstrophy for flows with no mass flux divergence. These two new options $(P S+E E N)$ have a drastic impact on the model solution, as it will be demonstrated in Section 3.

Other options worth noting in ORCA-R025 and all DRAKKAR configurations are; $(i)$ a TVD (Total Variance Diminishing) advection scheme for tracers (Levy et al., 2001) which, compared to the centred scheme, avoids the generation of overshoots in case of sharp gradients; (ii) a laplacian lateral isopycnal diffusion on tracers $\left(300 \mathrm{~m}^{2} \mathrm{~s}^{-1}\right.$ at the equator and decreasing poleward proportionally to the grid size), and (iii) a horizontal biharmonic viscosity for momentum $\left(-1.5 \times 10^{11} \mathrm{~m}^{4} \mathrm{~s}^{-1}\right.$ at the equator and decreasing poleward as the cube of the grid size). In the equatorial wave guide, a laplacian viscosity $\left(500 \mathrm{~m}^{2} \mathrm{~s}^{-1}\right)$ is added to the biharmonic operator at levels included in the upper $100 \mathrm{~m}$, to better control the speed of the equatorial undercurrent. This method gave satisfying results in the CLIPPER model (Arhan et al., 2005).

Surface boundary layer mixing and interior vertical mixing are parameterised according to a turbulent closure model (order 1.5) adapted to OPA by Blanke and Delecluse (1993). In case of static instability, a viscosity/diffusivity enhancement up to $10 \mathrm{~m}^{2} . \mathrm{s}^{-1}$ is used.

\section{Forcing}

The atmospheric forcing which drives the simulations presented here is a climatological seasonal cycle forcing applied in a cycling way. It is the same forcing used by Timmermann et al. (2005) in their application of older versions of OPA and LIM at coarser resolution $\left(2^{\circ}\right)$, except for the wind forcing which here, uses ERS scatterometer winds. 
Surface momentum flux is directly provided to the ocean/sea-ice model as a wind stress vector. A climatological daily mean wind stress vector is used. It is a combination of ERS Scatterometer data (CERSAT, 2002) and NCEP/NCAR re-analysis (Kalnay et al., 1996) built as follows: ERS wind stress between $50^{\circ} \mathrm{N}$ and $50^{\circ} \mathrm{S}$, a linear combination of ERS winds with NCEP between $50^{\circ}$ and $60^{\circ}$, and NCEP winds poleward of $60^{\circ}$. The daily climatology is built using years 1992 to 2000 with a 11 days running mean filter to remove synoptic variability.

Surface heat fluxes (solar, infrared, latent and sensible heat) and freshwater flux for ocean and sea-ice are calculated using the empirical bulk parameterisation described by Goosse (1997). Evaporation is derived from the latent heat flux. The set of atmospheric variables used in these flux calculations consists of: climatological daily mean values of air temperature from NCEP/NCAR re-analysis; climatological monthly mean precipitation from CMAP (Xie et Arkin, 1997); monthly mean humidity (Trenberth et al., 1989) and cloud cover (Berliand and Strokina, 1980), climatological daily mean wind speed from the blend of ERS and NCEP/NCAR reanalysis described above. River runoff was provided by MERCATOR-Ocean (Remy, personal communication). No relaxation to any sea surface temperature (SST) or sea surface salinity (SSS) is used.

\section{Performance}

ORCA-R025 is implemented on a massively parallel machine at IDRIS ${ }^{4}$. We applied a domain decomposition technique and split the global computational domain into $18 \times 12$ sub-domains (216 in all). To streamline efficiency, we use only processors having ocean grid points (186 processors). Each processor thus has $82 \times 87 \times 46$ grid points. A one row overlapping halo (1 row) is shared with the neighbouring processors, using explicit communications between processors, (MPI library). Figure 1 gives a global view of the domain broken-down into individual processors. The time step of the ocean component is $1440 \mathrm{~s}$ (60 time steps per day), and the seaice component is called once every 5 time steps. One year of model simulation requires $2200 \mathrm{~h}$ CPU on 186 IBM SP4 processors, and takes about $12.6 \mathrm{~h}$ of elapsed time. Maximum memory is $0.479 \mathrm{~Gb}$ per processor, and total memory is $84 \mathrm{~Gb}$.

\footnotetext{
${ }^{4}$ Institut du Dé veloppement et des Ressources en Informatique Scientifique, Orsay, France.
} 


\subsection{Sensitivity tests with ORCA-R025}

A series of 10-years simulations have been run to evaluate the contribution of various numerical choices to the solution. The focus is on the partial step representation of topography and the EEN vorticity scheme used in the calculation of momentum advection, which produced the greatest improvements to the model solution. Therefore we compare (in Section 3) a simulation which does not include these two features, referred to as G04, with a simulation which includes both, referred to as G22, (Table 1). Other numerical options were tested. In particular a full step simulation using the EEN vorticity scheme was run (simulation G03, Table 1) so the effects of the partial step could be separated. Some of results from this experiment will be used in the Section 3.

Table 1: List of the 10 year long sensitivity experiments carried out with ORCA-R025. The present mainly uses the results from the G04 and G22 simulations. No relaxation to SSS is applied in any of these experiments. A free slip side-wall boundary condition is used in all simulations.

\begin{tabular}{|l|c|c}
\hline \multicolumn{1}{|c|}{ Simulation } & Vorticity Scheme & Bottom Topography $^{*}$ \\
\hline G03 & EEN (new) & FS - Full Step \\
\hline G04 & ENS (old) & FS - Full Step \\
\hline G22 & EEN (new) & PS - Partial Step \\
\hline
\end{tabular}

Before we provide (in section 3) an assessment of the changes induced by the numerics, we provide a brief overview of simulation G22 (with partial steps and the EEN momentum advection scheme). Our analysis will remain rather descriptive. A full understanding of how the numerics impact on the physics of the model requires a large number of sensitivity experiments and complex diagnostics which are currently under way in a North Atlantic configuration of the code (Le Sommer et al., 2006). Preliminary results from this work are used in the discussion of Section 4 to illustrate possible reasons of improvements when the combination $P S+E E N$ is used

\subsection{Mean general circulation in simulation G22}

\section{Upper ocean circulation}

A first overview of the large scale upper circulation is presented in Figure 2 with a snapshot of the sea surface height $(s s h)$ and sea-ice cover in year 10 of the simulation. It shows the known general circulation features that are seen in similar model simulations (Maltrud et al., 1998, 
Maltrud and McClean, 2005): the well marked subpolar and subtropical gyres, the strong and meandering western boundary currents, the large upwelling systems of eastern ocean basins, the equatorial current systems with waves and eddies. The strong Antarctic Circumpolar Current (ACC, almost a $2 \mathrm{~m}$ change in $s s h$ ) shows many mesoscale features. Agulhas Rings are drifting northwestward in the South Atlantic. Western boundary currents, the North Brazil Retroflection area and the Caribbean Sea are rich in mesoscale features. Loop Current eddies are found in the Gulf of Mexico.

The distribution of the eddy kinetic energy (eke) compares remarkably well with the satellite estimate of Ducet et al. (2000) considering the medium resolution $\left(1 / 4^{\circ}\right)$ of the model (Figure 5). There are regions where a significant improvement is found compared to other experiments (see next section). One is the Brazil-Malvinas Confluence Zone in the South Atlantic, with the characteristic C-shape and the minimum of eke inside the Zapiola anticyclone (de Miranda et al., 1999). Another is the Agulhas region, where the paths of Agulhas Rings tend to be more realistic than in experiments with full step topography. The Gulf Stream and the North Atlantic Current system are also regions where the distribution pattern of $e k e$ is clearly improved, in particular in the Northwest Corner. As shown in following sections the distribution pattern of $e k e$ is sometimes better in simulation $\mathrm{G} 22$ than in $1 / 6^{\circ}$ and even $1 / 10^{\circ}$ experiments.

Sea-Ice is not the focus of the present paper, and only a quick overview is presented (the Austral winter sea-ice cover is shown in Figure 2). A first look at the sea ice component of simulation G22 shows reasonable performance in high latitudes. In the Arctic, the climatological winter sea ice extent, area and thickness are reproduced quite well, with many small scale details in the marginal ice zone present (e.g., ice tongues in the Greenland Sea, off Newfoundland and in the Okhotsk Sea, partial coverage of the Baltic Sea). The summer ice distribution is characterised by a general overestimation of the ice cover. For the Antarctic Marginal Seas, we find larger differences between observed climatology and the model results. While the winter extent is acceptable, the thickness shows a systematic bias: too thick in all coastal regions and too thin off-shore. The former leads to an overestimation in ice surviving the summer. Simulations with other global configurations of NEMO (at $1 / 2^{\circ}$ and $2^{\circ}$ resolutions) run within the DRAKKAR project show that this is a general feature of the coupled model system, not related specifically to the high resolution case presented here. It will be investigated in more detail in a separate study.

\section{Meridional circulation}

The meridional overturning cell or streamfunction (MOC) and the meridional heat transport (MHT) provide a zonally averaged view of the meridional circulation. They are quantities of 
important climate relevance that ocean models aim to simulate accurately. In 10-year long simulations as presented here, these quantities are still far from a state of equilibrium. However, they are systematically analysed in similar model studies (Maltrud and McClean, 2005; Lee and Coward, 2003). An initial assessment of the strength of the meridional circulation in our model is useful since it characterises the global dynamical regime in which simulations are compared.

We choose to comment on simulation G22, because it is representative of all three simulations in that respect, the MOC being very similar in simulations G03, G04. Note that the simulations discussed here do not include a bottom boundary layer to improve the deep overflows, usually not well reproduced in z-coordinate models.

The MOC and MHT of G22 are shown in Figures 3 and 4. It is very clear from Figure 4 that the simulation is still far from equilibrium, as displayed by the large discrepancies between the advective MHT (i.e. estimated from correlation of the meridional velocity with the temperature) and the MHT diagnosed from the meridional integration of the surface fluxes (under the hypothesis of a state of equilibrium). These differences are indicative of significant trends in the model heat storage.

In the Atlantic the maximum overturning is $24 \mathrm{~Sv}$ (Figure 3a), with over $6 \mathrm{~Sv}$ of dense water overflow across the sills of the Nordic Seas. The meridional oveturning cells of G03 and G04 (not shown) are identical to that of G22 in that respect. These values are in the upper bounds of the values found in the literature, indicating a particularly strong meridional circulation in the northern North Atlantic under the present forcing conditions in all our simulations. The southward flow of North Atlantic Deep Water (NADW) shows a significant decrease in the South Atlantic, from $16 \mathrm{~Sv}$ at the equator to $9 \mathrm{~Sv}$ at $30^{\circ} \mathrm{S}$. Northward flow of AABW is $4 \mathrm{~Sv}$ below $3800 \mathrm{~m}$. The maximum MHT is $1.28 \mathrm{PW}$ at $28.5^{\circ} \mathrm{N}$ (Figure 4a), a realistic value at this latitude. However, the MHT is generally weaker than the estimates obtained by an inversion of hydrographic sections by Ganachaud and Wunsch (2003). The comparison of the advective MHT with the MHT diagnosed from surface fluxes indicates a heat storage (i.e. warming) of the North Atlantic at latitudes higher than $30^{\circ} \mathrm{S}$, and a cooling elsewhere (between $30 \mathrm{~S}$ to $30^{\circ} \mathrm{N}$ ). The model is thus far from adjusted to the forcing field, limiting a quantitative interpretation of the above numbers.

In the Indo-Pacific, the MOC structure of G22 (Figure 3b) as well as those of G034 and G04 (not shown) shows a relatively deep reaching shallow overturning cell; the equatorward subsurface flow which compensates the poleward Ekman transport spreads down to $500 \mathrm{~m}$. The equatorial upwelling is quite strong. Beneath the shallow cell, there is almost no net cross 
equatorial transport above $3500 \mathrm{~m}$, the equatorial upwelling reaching almost to that depth. Below $4000 \mathrm{~m}$ the northward flow of bottom water crossing the equator is of the order of $12 \mathrm{~Sv}$.

The MHT maximum divergence (i.e. zero crossing) is located at about $4^{\circ} \mathrm{N}$ (Figure $4 \mathrm{~b}$ ). The northern hemisphere maximum is $0.55 \mathrm{PW}$ northward at $20^{\circ} \mathrm{N}$. The poleward MHT is greater in the southern hemisphere, and reaches its maximum of $1.7 \mathrm{PW}$ at $13^{\circ} \mathrm{S}$. The quantitative agreement with Ganachaud and Wunsch (2003) estimates is certainly fortuitous. The discrepancies observed between the advective MHT and the MHT diagnosed from surface fluxes indicate that the Indo-Pacific basin is being cooled between $20^{\circ} \mathrm{N}$ and $60^{\circ} \mathrm{N}$ (i.e. the North Pacific sector), and between the Equator and $10^{\circ} \mathrm{S}$ (strong cooling). From the Equator to $20^{\circ} \mathrm{N}$ and from $10^{\circ} \mathrm{S}$ to $35^{\circ} \mathrm{S}$, the difference between the two curves of Figure $4 \mathrm{~b}$ does not vary with latitude indicating a quasi equilibrium between the surface flux and the model heat transport.

At global scale, the MHT (Figure 4c) shows a relatively good symmetry with regard to the equator, a pattern common to estimates obtained from atmospheric analyses (see Trenberth and Caron, 2000, for example), with a large maximum of southward heat transport in the southern hemisphere $\left(1.5 \mathrm{PW}\right.$ at $\left.13^{\circ} \mathrm{S}\right)$. Global models usually tend to produce smaller values for the southern hemisphere maximum MHT (1.2 PW at $12^{\circ} \mathrm{S}$ in the $1 / 10$ POP model for example), in agreement with the hydrographic estimate of Ganachaud and Wunsch (2003). Note that an experiment similar to G22 but using a relaxation of SSS to climatological value reduced the southern hemisphere maximum to a value comparable to hydrographic estimates. The sensitivity of MHT to the details of the forcing is thus quite large.

The comparison with the global MHT diagnosed from surface fluxes (Figure 4c) suggests a quasi-equilibrium between heat advection and surface fluxes north of $20^{\circ} \mathrm{N}$. In fact, this equilibrium at the global scale is the result of a balance between the warming of the North Atlantic and the cooling of the North Pacific. Between $20^{\circ} \mathrm{N}$ and $20^{\circ} \mathrm{S}$, the global ocean is cooling, the Atlantic providing the major contribution to this cooling from $20^{\circ} \mathrm{N}$ to the Equator, and the contribution of the Indo-Pacific being dominant from the Equator to $20^{\circ} \mathrm{S}$. The imbalance between both MHT estimates is of the order of $1.0 \mathrm{PW}$ at $60^{\circ} \mathrm{S}$, mainly coming from the cooling at tropical latitudes. It will be interesting to see in future sensitivity experiments with different forcing fields how the MHT characteristics presented here are modified.

This brief overview of the model solution indicates that the ORCA-R025 broad circulation patterns correspond to what is expected from a state of the art ocean general circulation model. It also shows that the global meridional circulation, yet too far from steadiness to be quantitatively interpreted, is of very similar strength in all ORCA-R025 simulations 
compared here, so changes in the MOC intensity between experiments will not be an issue when comparing their respective regional circulation features.

\section{Effects of Partial Steps and EEN vorticity scheme}

We assess of the impact of the $P S$ and $E E N$ advection scheme on the model solution by looking at local dynamical circulation features whose spin-up is almost complete after 10 years, and whose characteristics should not change significantly (i.e. not to the point of invalidating the conclusions of the present study) during the slow adjustment of the internal thermohaline structure of the ocean to the forcing.

\subsection{Global analysis}

To identify where the $P S$ and the EEN vorticity scheme produce significant changes in the model solution, we compare the 3-year mean barotropic streamfunction (BSF) of simulations G22 and G04 (Figure 6a). To separate the effects of $P S$ and $E E N$, we also do this comparison for simulations G03 and G04 (Figure 6b), both using FS but G03 only using the EEN scheme (See Table 1). Only changes above $10 \mathrm{~Sv}$ are looked at here, which limits our investigation to regions of strong currents (i.e. where the impact of non-linear terms is strong). The first look at Figure 6a identifies the region around Antarctica as a region of great impact of the new schemes, the use of which reduces the ACC transport (from $160 \mathrm{~Sv}$ to $140 \mathrm{~Sv}$ at Drake Passage). This reduction is clearly due to the partial steps since the map of the BSF differences between the two full step simulations, which only differ by the momentum advection scheme (G03 and G04, Figure 6b), does not show this pattern. The smaller transport at Drake Passage in G22 (141 Sv compared to $154 \mathrm{~Sv}$ in G04) is therefore a consequence of the partial step topography. This is consistent with former studies which demonstrated how crucial the bottom topography is to establish the momentum balance of the ACC (Rintoul et al., 2001, Grezio et al., 2005).

Other regions of great differences are basically the regions of high eke levels shown in Figure 5: western boundary current systems with the largest impact in the Argentine Basin and the Gulf Stream, the Agulhas Current retroflection region and its extension in the southern Indian ocean, the most intense branches of the ACC in the Indian Ocean sector, in the Pacific Ocean sector around the Campbell Plateau and beyond. Smaller changes, still significant since slightly above $10 \mathrm{~Sv}$, are seen in the Labrador Sea, mainly due to the use of partial steps as deduced from Figure 6a,b. This is consistent with the findings of Käse et al. (2001) and Myers (2002) who 
showed that the use of partial step topography strengthened the North Atlantic subpolar gyre. Changes in $B S F$ are also noticeable in the Caribbean Sea and in the east Australian Current.

All the above remarks strongly suggest that the impact of the new schemes is localised where the flow is highly non-linear, and where the topographic constraint is strong, as briefly illustrated in Section 4 (see Le Sommer et al., 2006, for detailed explanations of this). Figures $6 a, b$ indicate that except for the region around Antarctica where the partial step topography appears to drive the changes, the EEN advection scheme and $P S$ have comparable contribution.

In the following, we concentrate our analysis on 6 regions (outlined in Figure 6a) where changes are particularly large. The impact of $P S$ and $E E N$ on the mean circulation will be assessed by comparing mean sea surface height ( $m s s h)$ and the mean eddy kinetic energy ( $e k e)$ of simulation G22 with estimates from observations and from various model experiments. The "observed" mssh used here as reference is the output of the surface drifter and satellite altimetry analysis of Niiler et al. (2003). The "observed" eke used here as reference is that derived from satellite altimetry by Ducet et al. (2000). Although referred to as "observed" quantities in the following, we should keep in mind that these are estimates derived from observations, and that they have their own inaccuracies and biases generally depending on data coverage (which is quite unequal from a region to another for surface drifters). Model results used are from simulations G04 and G22 performed with the ORCA-R025 model (Table 1), and from simulations carried out with different models: the OCCAM model (Webb et al., 1998, Coward and de Cuevas, 2005), the POP1/10 model (Maltrud and McClean, 2005) and the Clipper ATL6 model (Penduff et al., 2005). The main characteristics of these latter models are summarised in Table 2. Note that the version of OCCAM uses partial steps and a large number (66) of vertical levels.

Table 2: Main characteris tics of the 10 year long sensitivity experiments, G22 and G04, carried out with ORCA R025, and of the other model simulations compared in this study.

\begin{tabular}{|l|c|c|c|c|c|}
\hline \multicolumn{1}{|c|}{ Model Name } & Code & Area & Resolution & Topography & $\begin{array}{c}\text { Momentum } \\
\text { Advection }\end{array}$ \\
\hline G22 - ORCA-R025 & NEMO & Global & $1 / 4^{\circ}$ & Partial Step & $\begin{array}{c}\text { EEN } \\
\text { (Arakawa \& Lamb 1981) }\end{array}$ \\
\hline G04 - ORCA-R025 & NEMO & Global & $1 / 4^{\circ}$ & Full Step & $\begin{array}{c}\text { ENS } \\
\text { (Sadourny, 1975) }\end{array}$ \\
\hline OCCAM & MOM & Global & $1 / 4^{\circ}$ & Partial Step & Flux form \\
\hline POP1/10 & POP & Global & $1 / 10^{\circ}$ & Full Step & Flux form \\
\hline ATL6 & OPA8.1 & Atlantic & $1 / 6^{\circ}$ & Full Step & $\begin{array}{c}\text { ENS } \\
\text { (Sadourny, 1975) }\end{array}$ \\
\hline
\end{tabular}


We have to mention here the OFES simulation (Ocean general circulation model For the Earth Simulator). It is a 50 year long simulation carried out on the Earth Simulator in Japan (Masumoto et al., 2004) with a global implementation of the MOM3 code at $1 / 10^{\circ}$ resolution (thus similar to POP1/10). OFES outputs were not available when we carried out our analyses so this simulation is not included in the present study. However, public internet access ${ }^{5}$ to the OFES 50-year climatological simulation is now available. This simulation uses a Partial Step topography, and OFES mean fields could in future studies, be compared to the POP1/10 solution to assess the impact of the partial steps at eddy-resolving resolution. We mention some results of this simulation in section 3.2 .

\subsection{The Gulf Stream and North Atlantic Current System}

Figure 7 shows several mssh estimates obtained from observations (Figure 7a) and from various model experiments (Figures 7b-f). Observed characteristics of the mean path of the Gulf Stream outlined in Figure 7a are; a clear separation at Cape Hatteras, an elongated anticyclonic southern recirculation cell, the presence of a cyclonic northern recirculation cell indicating the presence of cold slope waters on the Grand Banks, and a crossing of the $40^{\circ} \mathrm{N}$ line at $60^{\circ} \mathrm{W}$. Beyond this point, the path of the NAC is characterised by a well marked Mann Eddy at $\left[42^{\circ} \mathrm{N}, 43^{\circ} \mathrm{W}\right]$, and a North West Corner at $\left[50^{\circ} \mathrm{N}, 40^{\circ} \mathrm{W}\right]$. Thus east of $40^{\circ} \mathrm{W}$ the path of the NAC is always north of $50^{\circ} \mathrm{N}$ and follows the topography.

The ORCA-R025 simulation G22 (which includes $P S+E E N$ ) reproduces rather well all these features (Figure 7b), except for the separation of the Gulf Stream, which still shows a slight overshoot and standing inertial oscillations in the current characterized by a standing eddy off Cape Hatteras (the unrealistic Hatteras eddy). Nevertheless, the transport of the Hatteras eddy (20 Sv in G22) is significantly reduced compared to the simulation without the new schemes (55 $\mathrm{Sv}$ in simulation G04 in Figure 7d), and even compared to the solutions provided by other models at similar resolution (OCCAM in Figure 7c) or higher resolution (POP1/10 and ATL6 in Figure 7e,f). Concerning the other observed characteristics of the Gulf Stream and the NAC, the G22 simulation is by far the most consistent with observations. The path of the mean current in G22 (including the northwest corner and the presence of slope waters) is remarkably accurate for a model of such resolution, despite a weaker Mann Eddy and a stronger $m s s h$ gradient between the subtropical and subpolar gyre.

\footnotetext{
${ }^{5}$ http://www2.es.jamstec.go.jp/ofes/eng/index.html
} 
Figure 8 shows several estimates of the $e$ ke obtained from satellite altimeter observations (Figure 8a) and from various model experiments (Figures 8b-f). In numerical models, the value of this quantity depends on how well the deformation radii are resolved (i.e. on the fact that the model is eddy resolving, like POP1/10, or eddy permitting, like ORCA-R025 or OCCAM). Therefore comparing eke levels between models must be moderated by considerations about their differences in resolution. The present analysis gives more attention to the distribution pattern of eke, which reflects the position of the main currents and eddy pathways, rather than comparing values.

The distribution of eke confirms the improvements due to the partial step and the EEN advection scheme to the simulation of the mean currents. Among all $1 / 4^{\circ}$ simulations presented here (G22, G04 and OCCAM), G22 is the one whose eke pattern (Fig. 8b) is the most consistent with observations (Fig. 8a), in particular along the path of the NAC. Simulation G04, performed with the same model without the new numerical methods is clearly deficient with regard to the path of the Gulf Stream beyond the Grand Banks. OCCAM shows extremely intense standing eddies at the separation point of the Gulf Stream. The eke pattern in the path of the NAC and the Northwest Corner indicates that this current system is shifted southward, a picture which is usual at this resolution for the MOM model. Interestingly, models with higher resolution do not perform better in terms of eke distribution pattern. Both POP1/10 and ATL6 show a strong eke maximum at the Gulf Stream separation point and a wide spread of eke East of the Grand Banks. This indicates a misrepresentation of the main path of the NAC. Note however that in a regional simulation of the North Atlantic carried out with the POP model at $1 / 10^{\circ}$ resolution by Smith et al. (2000), the path of the Gulf Stream was quite realistic and the distribution of eke was very comparable to the one observed from satellite.

Therefore, the distribution of the eke satellite estimate confirms the picture provided by the observed mssh that the use of $P S$ and EEN advection has considerably reduced the major dynamical biases found in the simulation of the current system of the western North Atlantic by most numerical models.

\subsection{Western South Atlantic}

Observed and model mssh estimates are shown in Figure 9 for the western South Atlantic. Improvements due to $P S$ and $E E N$ in the South Atlantic are even more striking than for the North Atlantic, in particular because the G22 experiment (Figure 9b) is the only one among all other models to reproduce the high $m s s h$ anomaly observed in the centre of the Argentinian Basin at $\left[45^{\circ} \mathrm{W}, 45^{\circ} \mathrm{S}\right]$ (Figure 9a). This high pressure pattern is the signature of the standing Zapiola 
Eddy, first reported from observations by Saunders and King (1995), and clearly seen in float data (Boebel et al., 1999). The first realistic simulation of the Zapiola Eddy was obtained with a sigma coordinate model by de Miranda et al. (1999) with a resolution of $1 / 3^{\circ}$. These authors demonstrated that this strong flow pattern, which transports over $100 \mathrm{~Sv}$, is the result of an interaction between the eddies generated in the highly turbulent confluence of the Brazil and the Malvinas currents, with the Zapiola drift, a deep depositional topographic feature rising only $1000 \mathrm{~m}$ above the abyssal plain of the Argentinian Basin. In agreement with the theory developed by Dewar (1988), the convergence of the eddy mass flux above the Zapiola drift generates a high pressure above the topography and a large anticyclonic circulation around it. The circulation pattern reaches its equilibrium when the eddy mass flux is balanced by the export of mass in the Ekman bottom boundary layer. De Miranda et al. (1999) suggested that standard zcoordinate models (i.e. using full step topography) could not simulate this feature because of a poor representation of $f / h$ contours and an increased numerical dissipation due to lateral friction induced by the step-like topography. This has since been confirmed with the ATL6 model simulations (Penduff et al., 2005), and the POP1/10 experiment (Maltrud and McClean, 2005), which could not reproduce this first order feature despite a significantly higher resolution. Our G03 simulation which includes the EEN vorticity scheme but uses a full-step topography, (see Table 1) does not either reproduce the Zapiola eddy. Comparing the BSF differences of Figure 6a and Figure 6b, it becomes obvious that the use of Partial Step topography is required to simulate this circulation pattern, in agreement with the discussion of de Miranda et al. (1999).

This requirement may not be sufficient since OCCAM does not reproduce the Zapiola eddy despite a $P S$ formulation of the topography. A reason could be that the no-slip boundary condition used by default in the MOM code prevents the formation of the anticyclonic circulation, known to be very sensitive to bottom dissipation (De Miranda et al., 1999). Still, the OCCAM results are contradicted by those of the OFES simulation (Masumoto et al., 2004), since this $1 / 10^{\circ} \mathrm{MOM} 3$ global simulation with partial cell topography simulates a well marked Zapiola eddy (Sasaki, personal communication). Understanding the behaviour of the PS version of the MOM code is likely challenging, and certainly deserves a specific investigation.

In addition to the Zapiola Eddy, the representation of the Malvinas and Brazil currents confluence is also significantly improved with PS and EEN (simulation G22, Figure 9b) when compared to G04. This improvement is also remarkable when compared to solutions produced by the other models, including POP1/10 and ATL6 which used much higher resolution $\left(1 / 10^{\circ}\right.$ and $1 / 6^{\circ}$ respectively). G22 is the only simulation for which the Confluence region is offshore of 
the Rio de La Plata $\left(36^{\circ} \mathrm{S}-38^{\circ} \mathrm{S}\right)$. In every other simulation, independent of the numerical model used and of resolution, the Confluence region is located south of $40^{\circ} \mathrm{S}$ (and as far as $43^{\circ} \mathrm{S}$ ).

The distribution pattern of $e k e$ (Figure 10) confirms this picture. Simulation G22 and Topex/Poseidon exhibit very similar distributions, with the characteristic C-shape of high eke levels around the core of the Zapiola Eddy and small eke levels above. Other models, in particular OCCAM and ATL6, exibit eke patterns characteristic of a strong overshoot to the south of the Brazil Current, and no sign of the Zapiola Eddy.

\subsection{Cape Basin}

The simulation of the Agulhas current system is also greatly influenced by the new numerical schemes. First the stability of the Agulhas Current as it flows along South Africa is clearly different in simulations G22 and G04, as illustrated by the snapshots of current speed shown in Figure 11. When PS and EEN advection are not used (simulation G04, Fig. 11b) the Agulhas Current resembles a train of large eddies rather than a continuous stream as in G22 (Figure 11a). In G04, the retroflection produces pairs of very large eddies (or rings) which later drift into the South Atlantic. The ring generation is very regular in time, rings shed from the retroflection are quite large in size and all use the same pathway to the northwest. Their signature in the distribution of $e k e$ (Figure 12d) is a band of high eke stretching from the retroflection region across the Cape basin. The ring generating process is dominated by shear instability. This picture is that usually provided by eddy permitting numerical models since the FRAM experiment (Stevens and Kilworth, 1992), with the very few exceptions of the regional models of Biastoch and Krauss (1999) and De Miranda et al. (1999b), which although at slightly coarser resolution $\left(1 / 3^{\circ}\right)$, did not show that bias. In these later regional experiments, the shear instability could be under-estimated due to a lack of resolution. More recent models based on the same numerical code from GFDL (OCCAM in Fig. 12c or POP1/10 in Fig. 12e), and on the OPA8.1 code (at $1 / 3^{\circ}$ resolution, Treguier et al., 2001) also present the same type of bias. The ATL6 $\left(1 / 6^{\circ}\right)$ model simulations run with OPA8.1 during the CLIPPER project provided a better representation of the Agulhas retroflection region (Treguier et al., 2003). It is possible that the use of a climatological open boundary across $30^{\circ} \mathrm{E}$ in this later simulation prevented the growth of the inertial eddies seen in Fig. 11b, resulting in a better simulation of the Agulhas Current. Nevertheless, the path of the Agulhas Rings in the South Atlantic was not correctly simulated.

The picture of the circulation in this region provided by simulation G22 with the PS and EEN scheme is significantly different from those described above, and is more consistent with observations. In the snapshot of the current speed shown in Fig. 11a, the Agulhas retroflection 
appears as a large loop of a continuous stream, which extends into the south Atlantic sometimes as far as $16^{\circ} \mathrm{E}$ before it closes and sheds from the main stream. After shedding, this loop breaks into smaller eddies (the Agulhas Rings). Although the above scenario is by far the most frequent during the 10 years of the G22 simulation, we noticed a few periods when the Agulhas Current behaved in a way similar to that observed in G04. But overall, the eddy field in G22 is more chaotic than in G04, Agulhas Rings being rarely produced by pair and their path across the South Atlantic not being as regular. We expect to reach a more complete understanding of the model behaviour with the longer interannual CORE forcing experiment (50 years) that will be performed in the near future.

Discrepancies noted above regarding the generation and pathway of the Agulhas Rings have drastic consequences on the Cape Basin eke distribution shown in Figure 12. The eke pattern of simulation G22 (Fig. 12b) is by far the most consistent with that provided by satellite altimetry (Fig. 12a), although a tendency for a preferred path of the eddies in their westward drift still remains. As in satellite observations, largest $e k e$ values in G22 are found in the retroflection loop and in the returning Agulhas Current. In the other model simulations, quite large eke values are also found along the east African coast (i.e. in the Agulhas Current before the retroflection loop) and in the path of the rings in the South Atlantic, features not found in the Topex/Poseidon data. Maps of mssh (not shown) show a main path of the returning Agulhas Current along the northern flank of the Agulhas Plateau in simulation G22, very similar to that of the observed $m s s h$ of Niiler et al. (2003). This explains the "pinching" of the $e k e$ pattern at $\left[25^{\circ} \mathrm{E}, 39^{\circ} \mathrm{S}\right]$, high $e k e$ levels being found at the north side of the plateau in the mean current, minimum eke levels being found on the plateau itself. The other models do not show such "pinching" of the $e k e$ pattern at the Agulhas Plateau, which suggests that the G22 simulation is more realistic in accounting for the effects of topography on the mean flow.

\subsection{Kuroshio}

The simulation of the mean position of the Kuroshio along the coast of Japan is improved by the new schemes. The comparison of the mssh simulated by experiments G22 (Fig. 13b) and G04 (Fig. 13c) shows that G22 is again closer to the observations (Fig. 13a). In this latter simulation, location and meandering of the main stream along the Ryukyu Archipelago and southern Japan (i.e. before the current separates from the coast of Japan) compare very well with observations. The separation is marked by a slight overshoot with two standing eddies aligned offshore, and the path of the mean current is shifted $1^{\circ}$ north of the observed position. Without $P S$ and $E E N$ advection (simulation G04), the overshoot and the mean current location are shifted even more to 
the north, and the standing eddies are now aligned along the coast reaching beyond $40^{\circ} \mathrm{N}$. This is reflected in the pattern of the $B S F$ difference of Figure 6a, which shows negative values (i.e. reduced transport) on the north side along the Kuroshio extension and positive values (i.e. increased transport) on the south side. This indicates a southward shift of the mean current path in simulation G22 compared to G04. The path of the Kuroshio after its separates from Japan is better located in POP1/10 (but not in OCCAM), but the intense high/low dipole of $m s s h$ south of Japan (also seen in OCCAM, Fig. 13c,e) is in strong disagreement with observations.

Eddy kinetic energy shows a significant reduction in the Kuroshio extension in simulation G22 (Fig. 5a). In the observations high eke levels are found much farther to the East (see Fig. 5b). POP1/10 (no figure shown, see Maltrud and McClean, 2005) simulates a rather realistic eastward extension of $e k e$ in the North Pacific ocean, indicating that simulating this feature could be more a resolution issue than a current topography interaction issue.

\subsection{South Indian Ocean}

The south Indian Ocean (the red box to the southwest of Australia in Fig. 6a) is another region where the BSF difference between simulations G22 and G04 shows a pattern indicating a meridional shift of the mean current. The bottom topography of the region (Fig. 15) is characterised by the Kerguelen Plateau in the southwest corner of the domain and the Amsterdam Island in the northwest corner at $\left[41^{\circ} \mathrm{S}, 78^{\circ} \mathrm{E}\right]$, from where the Southeast Indian Ridge (SIR) stretches to the southeast. The passage between the islands of Kerguelen and Amsterdam at $75^{\circ} \mathrm{E}$ features a rise of the bottom topography of $1500 \mathrm{~m}$ above the abyssal plains of the western and eastern Indian basins, and is likely to influence the path of the Antarctic Circumpolar Current (ACC) to the east.

The observed flow in the area can be described from the mssh of Niiler et al. (2003) shown in Figure 14 and the eke distribution obtained from Topex/Poseidon (Figure 15). The ACC enters this region passing between Kerguelen and Amsterdam as a broad current spreading between $45^{\circ} \mathrm{S}$ and $50^{\circ} \mathrm{S}$. In its eastward route, the main stream of the ACC makes a large meander at $80^{\circ} \mathrm{E}$ while the topography rises slightly between the Kerguelen-Amterdam passage. Further down stream, the ACC crosses the SIR between $90^{\circ} \mathrm{E}$ and $100^{\circ} \mathrm{E}$. It then tilts south eastward to flow along the northern flank of the ridge. The ACC shows significant $e$ e levels as it passes the Kerguelen Plateau (between $70^{\circ} \mathrm{E}$ and $90^{\circ} \mathrm{E}$ ), and after crossing the ridge (from $105^{\circ} \mathrm{E}$ to $120^{\circ} \mathrm{E}$, Figure $15 \mathrm{a}$ ). This circulation scheme is very consistent with that recently deduced from autonomous floats drifting at $900 \mathrm{mb}$ (Davis, 2005) suggesting a significant barotropic component of the flow. 
The $m s s h$ in simulation G04 (no $P S$ and no EEN advection) exhibits a similar behaviour to the observed one, the ACC crossing the SIR at the same location (Fig. 14c and Fig. 15c). OCCAM and POP1/10 simulations (no figure shown) are very similar to G04. However, both these models tend to produce more zonal flows and to show less sensitivity to the bottom topography. This is well illustrated by their respective eke patterns (Figure 15c,e) which do not exhibit the observed tilt according to the orientation of the SIR.

In contrast to the observed estimate, the $m s s h$ in simulation G22 reveals a strong topographic influence and a significant branching of the ACC (Fig. 14b). At the entrance of the domain $\left(75^{\circ} \mathrm{E}\right)$ the main stream of the ACC is split in two branches. One branch, not present in the observed $m s s h$, flows north up to Amsterdam Island where it crosses the SIR. It continues to flow south-eastward along the northern side of the ridge and significantly intensifies, probably by topographic influence between $80^{\circ} \mathrm{E}$ and $100^{\circ} \mathrm{E}$. The other branch, which enters the domain along the eastern Kerguelen Plateau, behaves in a way similar to the observed $m s s h$. The flow meanders eastward, part of it crossing the SIR in the same passage as suggested by the observed mssh between $90^{\circ} \mathrm{E}$ and $100^{\circ} \mathrm{E}$. The northward split of the ACC at the longitude of the Kerguelen Plateau is not related to $P S$ alone (although its contribution is dominant). Simulation G03 which uses the full step topography and the new EEN scheme already differs from G04 (Fig. 6b), and also shows this split of the ACC path (no figure shown).

The circulation branches described above correspond to regions of high eddy kinetic energy (Fig. 15). The high eke values seen in G22 on the northern side of the SIR in the $\left[80^{\circ} \mathrm{E}\right.$, $100^{\circ} \mathrm{E}$ ] longitude band (Fig. 15b) is the direct result of the instability of the northern branch of the ACC. In the eastern part of the domain $\left[100^{\circ} \mathrm{E}, 120^{\circ} \mathrm{E}\right]$, the eke is rather similar in pattern between G22, G04 and the estimate derived from altimeter observations; high eke values are found on the north side of the SIR, aligned along the topography.

Considering the remarkably good agreement of G22 with observations in most regions, this unrealistic behaviour of the ACC in this longitude band is rather disconcerting. It is likely that the behaviour of the northern branch, and in particular the intensification of the current by the strong topography of Amsterdam Island and the SIR, is the downstream consequence of the splitting of the ACC as it reaches the longitude of the Kerguelen Plateau. This split, which seems to be related to the topographic slopes, and its relation to the use of the PS and EEN numerical schemes, deserves a more detailed investigation.

The difference between the G22 and G04 simulations may be partly explained by the differences between the partial step and the full step representations of the topography of the Kerguelen-Amsterdam passage. Because the bottom depth is adjusted to the local z-level in the 
FS topography, a flat channel exists in G04 which connects the western and eastern abyssal plains at the depth of $3530 \mathrm{~m}$ (the $37^{\text {th }}$ level of the model). This channel does not exist in the original Etopo2 topography, nor in the PS topography, which both have a sill in the passage at the depth of nearly $3300 \mathrm{~m}$. The existence of this channel in G04 may influence the path of the ACC between the islands, which may thus agree with observations for the wrong reasons.

\subsection{Campbell Plateau}

The region south and west of New Zealand is also characterised by large changes in $B S F$ due to the use of both PS and EEN (Fig. 6). Major BSF changes between G22 and G04 are localised along the topography of the Campbell Plateau and the Chatham Rise (see the bottom topography map in Figure 16). Figure 17 shows the various estimates of mssh. As noted for most regions we have already looked at, there is a remarkable agreement between the observed mssh and that simulated in G22, the latter showing currents at finer scale. Every circulation feature, like the branching of the ACC at the tip of the Campbell Plateau $\left[55^{\circ} \mathrm{S}, 165^{\circ} \mathrm{E}\right]$, the trapping of the ACC on the slope of the east side of the Campbell Plateau, the well marked anticyclonic circulation far inside the Bounty Trough (reaching the coast of New Zealand and flowing out the trough along Chatham Rise), are reproduced. Even farther to the west (between $150^{\circ} \mathrm{W}$ and $130^{\circ} \mathrm{W}$ ), the model reproduces the ACC splitting into two branches while it crosses the Pacific Antarctic Ridge. The G04 simulation, although rather realistic in this region, does not show the same amount of details. In particular, flows trapped on topographic slopes are weaker. However, one could wonder whether the G22 could overemphasise the topographic constraint, as suggested for the South Indian region. This will have to be investigated in the future with additional in-situ data, and by looking at the baroclinic structure of the flow. Note that recent subsurface float observations presented by Davis (2005), (see his Fig. 3) show a very consistent circulation inside Bounty Trough, trapped on the topographic slope, very much like the circulation pattern simulated in G22. OCCAM and POP1/10 models do not simulate the flow with similar details, despite similar or higher resolution. In particular, the intrusion of the ACC into the Bounty Trough is not reproduced. An interesting model feature is the standing cyclonic eddy found in the abyssal plain south of the Campbell Plateau at $\left[55^{\circ} \mathrm{S}, 172^{\circ} \mathrm{E}\right]$. This feature is seen in every model, and corresponds in the observed $m s s h$ to a "flat" (i.e. no gradient) $m s s h$, separating two branches of the ACC. Models and observations are thus consistent indicating that the mean flow does not go through but around the abyssal plain. 


\section{Discussion and Conclusion}

We have provided an overview of progress in modelling the ocean general circulation at eddy permitting $\left(1 / 4^{\circ}\right)$ resolution, achieved within the European project DRAKKAR. The main focus has been on modelling issues whose importance was continuously emphasised by Christian Le Provost, which are the numerical treatment of non-linearities and bottom topography. We introduced this paper with a brief presentation of the DRAKKAR community project, in the birth of which Christian Le Provost actively participated. We have described the eddy permitting, global $1 / 4^{\circ}$ resolution, model configuration implemented by the project, ORCA-R025. This ocean/sea-ice general circulation model uses the NEMO code, which is a new version of the OPA primitive equation, z-level, ocean circulation model coupled to the LIM2 sea-ice model. The characteristic of the new code which is evaluated here lies in a new advection scheme for momentum equations (the EEN scheme) and the use of a partial step (PS) representation of the bottom topography. Ten-year long sensitivity simulations with and without EEN and PS numerics have been run with ORCA-R025 under a climatological atmospheric forcing. The impact of the new numerical choices on the model solution have been assessed by comparing the model mean sea surface height ( $m s s h$ ) and eddy kinetic energy ( $e k e)$ with their equivalent in the observations and with other state of the art model simulations at equivalent or higher resolution.

Although our analysis remained quite descriptive, it demonstrated that the combination of the $E E N$ scheme with $P S$ yields a remarkable improvement in the major circulation patterns. Well known biases in the representation of western boundary currents, such as in the Atlantic, the separation of the Gulf Stream, the path of the North Atlantic Current at the Northwest Corner, the location of the Brazil-Malvinas Confluence and the strength of the Zapiola Eddy, are significantly corrected. Similar improvements are found in the Pacific, Indian and Southern Oceans, and characteristics of the simulated mean circulation patterns are generally much closer to observations. In comparison with other models at similar resolution (the $1 / 4^{\circ}$ OCCAM), the ORCA-R025 configuration generally performs better. In addition, the ORCA-R025 solution is often comparable to (or even better than) solutions obtained at $1 / 6^{\circ}$ (CLIPPER model) or $1 / 10^{\circ}$ (POP Model) resolution in some aspects concerning mean flow patterns and distribution of eddy kinetic energy. Note that the improvements in $m s s h$ and $e k e$ presented here generally correspond to improvements in the deep circulation (not discussed in this paper), and in particular in a stronger and quite coherent deep western boundary current.

The impact of the new numerical schemes is not uniformly a positive one. The flow pattern of the ACC in the South Indian Ocean is different from that suggested by both mssh and 
eke observations when $P S$ and $E E N$ are used. Moreover, the solution with this later combination seems degraded when compared to the solution with the full step topography and the former ENS advection, although this could be due to compensating errors in the full step representation of topography. The unrealistic branching of the ACC at the longitude of the Kerguelen plateau (Section 3.5) suggests a strong local sensitivity of the model solution to the bottom topography which we yet do not understand. Additional simulations, driven by different atmospheric forcing produced a MOC and an ACC of different strength from G22, but still presented a similar flaw in the region, and the same happened with a different algorithm to calculate the pressure gradient between partial cells. Additional simulations are underway, but at present we are not able to explain this local behaviour of the solution.

The use of partial step topography and $E E N$ advection scheme thus dramatically affects the ORCA-R025 model solution in regions which are subject to strong current-topography interactions. Understanding in full the dynamical origin of these improvements is beyond the scope of the present paper, but first analyses point to the presence of small-scale noise near the bottom as a crucial factor. Fig. 18 shows a measure of the vertical velocity noise (the deviation of the vertical velocity from its 9-point average) in the Gulf Stream region as a function of depth (a similar picture is obtained in all regions of the global model). In all three cases (G03, G04 and G22) we find this noise to increase significantly towards the bottom. In the near bottom layer (approximately 8 levels up from the bottom) the noise is drastically reduced by the use of the EEN scheme in combination with partial step topography (G22). According to Le Sommer et al. (2006) it is plausible that the noise level has time-mean effects through the diffusion of momentum and tracer, and that the choice of bottom cell and advection schemes consequently affects the vertical energy distribution near sloping topography and thereby the larger scale flow.

We conclude that significant corrections of the mean biases seen in general circulation model solutions at eddy permitting resolution, which were not obtained by increasing resolution, have been obtained by changing the numerical methods used. Studies searching for a full understanding of the impact of the EEN and PS numerics on the model dynamical solution are currently under way. Already, it has been shown that the impact of the EEN scheme is greatest at grid cells nearest a side wall (Le Sommer et al., 2006), suggesting a great sensitivity of the momentum advection to the lateral and bottom boundary condition. The numerical treatment of momentum advection has somewhat been overlooked in global and climate ocean models, except perhaps for the dynamics of the Equatorial undercurrent. This contrasts with numerous studies dealing with the importance of advection schemes for temperature, salinity and other tracers (see for example, Levy et al., 2001). It also contrasts with the regional model ROMS where special 
effort has been put into developing new advection schemes for momentum (Schepekin and Mc Williams, 2005).

In recent years, improvement of global ocean models has been sought through an increase in horizontal resolution, and global model simulations have been performed at $1 / 10^{\circ}$ and $1 / 12^{\circ}$ resolution (Maltrud and McClean, 2005, Kara et al., 2005, Coward and de Cuevas, 2005). Our results bring forward a different view and point out the numerical treatment of momentum advection and bottom topography, and more generally the improvement of the model numerics, as an issue of prime importance for eddy permitting climate modelling.

But eddy permitting models have been shown to perform worse than coarse resolution models in the representation of important small scale processes such as the re-stratification after a deep convection event (Chanut et al., 2006, Czeschel, 2005), or the deep overflows. It is clear that physical parameterisations developed at coarse resolution (for example the "bolus velocity" of Gent and McWilliams, 1990, or the "bottom boundary layer" of Beckmann and Dörscher, 1997) are not suited for that resolution. It is likely that development or adaptation of parameterisations of these key sub-grid-scale processes at eddy-permitting resolution should be co-ordinated with the development of numerics, since their efficiency could depend on the model numerical schemes.

The complexity of the global ice-ocean system is such that the sensitivity of an eddy permitting model is still poorly known. Nevertheless, it is expected that many ocean models used for climate prediction, which provide our only means to assess future changes, will begin to operate in the eddy-permitting regime within a few years. Hence developing an improved understanding of how this regime plays a key role in controlling global ocean dynamics has become a high priority.

\section{Acknowledgements}

This work is a contribution of the DRAKKAR project. Support to DRAKKAR comes from various grants and programs listed hereafter: French national programs GMMC, PATOM and PNEDC. PICS 2475 from Institut National des Sciences de l'Univers (INSU) and Centre National de la Recherche Scientifique(CNRS). Kiel SFB460 and CLIVAR-marin (03F0377A/B) supported by Deutsche Forschungsgemeinschaft. European integrated project MERSEA. Computations presented in this study were performed at Institut du Développement et des 
Ressources en Informatique Scientifique (IDRIS). Finally we would like to thank P. Niiler, N.A. Maximenko and J. C. McWilliams who kindly made their data sets available from the Web.

\section{References}

Adcroft A, Hill C, Marshall J (1997) Representation of topography by shaved cells in a height coordinate ocean model. Mon Wea Rev, 125, $2293-2315$

Arakawa A, Lamb VR (1981) A potential enstrophy and energy conserving scheme for the shallow water equations. Mon Wea Rev 109: 18-36

Arhan M, Treguier A-M, Bourles B, Michel S (2005) Diagnosing the annual cycle of the Equatorial Undercurrent in the Atlantic Ocean from a general circulation model. J Phys Oceanogr, in revision

Barnier B, Le Provost C (1993) Influence of bottom topography roughness on the jet and inertial recirculation of a mid-latitude gyre. Dyn of Atm and Oceans 18: 29-65

Beckmann A, Döscher R (1997) A method for improved representation of dense water spreading over topography in geopotential-coordinate models. J Phys Oceanogr. 27: 581-591

Berliand ME, Strokina TG (1980) Global distribution of the total amount of clouds,. Hydrometeorological, Leningrad, 71 pp. (in Russian)

Blanke B, Delecluse P (1993) Variability of the tropical atlantic ocean simulated by a general circulation model with two different mixed-layer physics. J Phys Oceanogr 23: 1363-1388

Blayo E, Le Provost C (1993) Performance of the capacitance matrix method for solving Helmholtz type equations in ocean modelling. J Comp Phys 104: 347-360

Boebel O, Davis RE, Ollitrault M, Peterson RG, Richardson PL, Schmid C, Zenk W (1999) The intermediate depth circulation of the western South Atlantic. Geophysical Research Letters, VOL. 26, NO. 21, PAGES 3329-3332

Böning CW, Bryan FO (1996) Large-scale transport processes in high resolution circulation models. in: The Warm Watersphere of the North Atlantic, Eds Gebrüder Borntraeger, Berlin, 91-128

Böning CW, Rhein M, Dengg MJ, and Dorow C (2003) Modeling CFC inventories and formation rates of Labrador Sea Water, Geophysical Research Letters, VOL 30(2), 1050, doi:10.1029/2002GL014855

Bryan FO, Holland WR (1989) A high resolution model of the wind- and thermohaline-driven circulation in the North Atlantic Ocean. In: Muller P, Henderson D (Eds.), Aha Huliko a Parameterization of Small-Scale Processes. Hawaii Institute of Geophysics, pp. 99-115

CERSAT (2002) Mean Wind Fields (MWF product) Volume 1 - ERS-1, ERS-2 \& NSCAT User Manual, Ref C2-MUT-W-05IF, Version : 1.0.

Chanut J, Barnier B., Large W, Penduff T, Molines JM (2006) Mesoscale Eddies in the Labrador Sea and their Contribution to Convection and re-Stratification. Submitted to J. Physical Oceanogr.

Coward AC, de Cuevas BA (2005) The OCCAM 66 level model: Model description, physics, initial conditions and external forcing. SOC Int. Rep. 99, Southampton Oceanogr aphy Centre, Southampton, U K

Czeschel L (2005) The Role of Eddies for the Deep Water Formation in the Labrador Sea. Ph.D. Thesis, Kiel University, Institut f. Meereswissenschaften, $101 \mathrm{pp}$.

de Miranda A, Barnier B, Dewar WK (1999) On the dynamics of the Zapiola Anticyclone. J Geophys Res - Ocean 104: 21,13721,149

de Miranda A, Barnier B, Dewar WK (1999b) Mode waters and subduction rates in a high resolution South Atlantic simulation.

J. Mar. Res., 57, 213-244 
Davis ER (2005) Intermediate-depth circulation of the Indian and South Pacific Oceans measured by autonomous floats. J Phys Oceanogr 35: 683-707

Dewar WK (1998) Topographic and barotropic transport control by bottom friction. J Mar Res 56: 295-328

Ducet N, Le Traon PY, Reverdin G (2000): Global high resolution mapping of ocean circulation from Topex/Poseidon and ERS1 and -2. J Geophys Res - Ocean 105 (C8): 19477-19498

DYNAMO Group (1997) DYNAMO: dynamics of the North Atlantic Models: simulationand assimilation with high resolution models. Ber Institute für Meereskunde, Universität Kiel, 294, 334pp

Fichefet T, Morales Maqueda MA (1997) Sensitivity of a global sea ice model to the treatment of ice thermodynamics and dynamics. J Geophys Res 102: 12609-12646

Ganachaud A, Wunsch C (2003) Large-scale ocean heat and freshwater transports during the World Ocean Circulation Experiment. J of Climate 16: 696-705

Gent PR, McWillams J C (1990) Isopycnal mixing in ocean circulation models. J Phys Oceanogr, 20: 150-155.

Goosse H (1997) Modeling the large scale behaviour of the coupled ocean-sea ice system. Ph.D. Thesis, Université Catholique de Louvain, Louvain-la-Neuve, Belgium, $231 \mathrm{pp}$.

Grezio A, Wells NC, Ivchenko VO, de Cuevas BA (2005) Dynamical budgets of the Antarctic Circumpolar Current using ocean general-circulation models. Quarterly Journal of the Royal Meteorological Society, 607, Part A, 833-860(28)

Jakobsson M, Cherkis NZ, Woodward J, Macnab R, Coakley B (2000) New grid of Arctic bathymetry aids scientists and mapmakers. Eos, Transactions, American Geophysical Union, v. 81, no. 9, p. 89, 93, 96

Jourdan D, Balopoulos E, Garcia-Fernandez MJ, Maillard C (1998) Objective Analysis of Temperature and Salinity Historical Data Set over the Mediterranean Basin, IEEE

Kalnay E, Kanamitsu M, Kistler R, Collins W, Deaven D, Gandin L, Iredell M, Saha S, White G, Woollen J, Zhu Y, Chelliah M, Ebisuzaki W, Higgins W, Janowiak J, Mo KC, Ropelewski C, Leetmaa A, Reynolds R, Jenne R (1996) The NCEP/NCAR 40-year reanalysis project. BAMS 77: 437-471

Kara AB, Barron CN, Martin PJ, Smedstad LF, Rhodes RC (2005) Validation of interannual simulations from the $1 / 8^{\circ}$ global Navy Coastal Ocean Model. Ocean Modelling in press.

Käse RH, Biastoch A, Stammer DB (2001) On the mid depth circulation in the Labrador and irminger Seas. Geophys Res Letters, $28: 3433-3436$

Large W, Yeager S (2004) Diurnal to decadal global forcing for ocean and sea-ice models: the data sets and flux climatologies. NCAR technical note: NCAR/TN-460+STR. CGD division of the National Center for Atmospheric Research.

Lee M M, Coward A C (2003) Eddy mass transport in an eddy-permitting global ocean model. Ocean Modelling, 5/3, 249-266

Le Sommer J, Penduff T, Madec G (2005) How momentum advection schemes affect current-topography interactions in the DRAKKAR 1/4-degree z-coordinate model. In preparation for ocean Modelling

Levitus S, Boyer TP, Conkright ME, O'Brian T, Antonov J, Stephens C, Stathopolos L, Johnson D, Gelfeld R (1998) World Ocean Database 1998. NOAA Atlas NESDID18.

Lévy M, Estublier A, Madec G (2001) Choice of an advection scheme for biogeochemical models, Geophys Res Lett, 28(19), 3725-3728, 10.1029/2001GL012947

Lythe MB, Vaughan DG (2001) BEDMAP: a new ice thickness and subglacial topograpic model of Antarctica. J Geophys Res Solid Earth 106: 11335-11351

Madec G, Imbard M (1996) A global ocean mesh to overcome the North Pole singularity. Climate Dyn, 12, 381-388

Madec G, Delecluse P, Imbard M, Levy C (1998) OPA 8.1 general circulation model reference manual. Notes de l'IPSL, Université P. et M. Curie, B102 T15-E5, 4 place Jussieu, Paris cedex 5, $\mathrm{N}^{\circ} 11,91 \mathrm{p}$

Maltrud ME, Smith RD, Semtner AJ, Malone RC (1998) Global eddy-resolving ocean simulations driven by 1985-1995 atmospheric fields. J Geophys Res - Oceans 103: 30,825-30,853

Maltrud ME, McClean JL ( 2005) An eddy resolving global 1/10 ocean simulation. Ocean Modelling 8: 31-54 
Marsh R, de Cuevas BA, Coward AC, Bryden HL, Alvarez M (2005) Thermohaline circulation at three key sections in the North Atlantic over 1985-2002. Geophys Res Letters, VOL. 32, L10604, doi:10.1029/2004GL022281, 2005

Masumoto Y, Sasaki H, Kagimoto T, Komori N, Ishida A, Sasai T, Miyama T, Motoi T, Mitsudera H, Takahashi K, Sakuma H, Yamagata T, (2004) A fifty-year eddy-resolving simulation of the world ocean: Preliminary outcomes of OFES (OGCM for the Earth Simulator). J Earth Simulator, 1, 35-56

Myers PG (2002) SPOM: A regional model of the sub-polar North Atlantic. Atmosphere-Ocean 445-463.

Murray RJ (1996) Explicit generation of orthogonal grids for ocean models. J Comput Phys., 126, 251-273

Niiler PP, Maximenko NA, McWilliams JC (2003) Dynamically balanced absolute sea level of the global ocean derived from near-surface velocity observations. Geophys Res Letters, VOL. 30, NO. 22, 2164, doi:10.1029/2003GL018628, 2003

Pacanowski RC, Gnanadesikan A (1998) Transient response in a z-level ocean model that resolves topography with partial cells. Monthly Weather Review 126:3248-3270

Penduff T, Barnier B, Verron J, Kerbiriou MA (2002) How topographic smoothing contributes to differentiating the eddy flows simulated by sigma- and z-level models. J Phys Oceanogr 32: 122-137

Penduff T, Barnier B, Madec G, Molines JM (2005) Validating a 1/6 ${ }^{\circ}$ CLIPPER simulation against the WOCE current meter dataset. Ocean Modelling in press.

Rintoul S.R, Hughes CW, Olbers D (2002) The Antarctic Circumpolar Current System. In Ocean Circulation and Climate, G. Siedler, J Church and J Gould (Eds), International Geophysic series, vol 77, Academic press

Roullet G, Madec G (2000) Salt conservation, free surface and varying volume: a new formulation for ocean GCMs. J Geophys Res, 105, 23,927-23,942

Sadourny R (1975) The Dynamics of Finite-Difference Models of the Shallow-Water Equations. Journal of Atmospheric Sciences, 32(4).

Shchepetkin AF, McWilliams JC (2005) Regional Ocean Model System: a split-explicit ocean model with a freesurface and topography-following vertical coordinate. Ocean Modelling, 9, 347-404

Smith RD, Maltrud ME, Bryan FO, Hecht MW (2000) Numerical simulation of the North Atlantic Ocean at $1 / 10^{\circ}$. J Phys Oceanogr 30: 1532-1561

Smith WHF, Sandwell DT (1997) Global sea-floor topography from satellite altimetry and ship depth soundings. Science 277: 1956-1962

Steele M, Morley R, Ermold W (2001) PHC: A global ocean hydrography with a high quality Arctic Ocean. Journal of Climate 14: 2079-2087.

Stevens DP, Killworth PD (1992) The distribution of kinetic energy in the Southern Ocean. A comparison between observations and an eddy-resolving general circulation model. Phil Trans Royal Soc B 338: 251-257.

Timmmerman A, Goosse H, Madec G, Fichefet T, Ethe C, Dulière V (2005) On the representation of high latitude processes in the ORCA-LIM global coupled sea-ice ocean model. Ocean Modellin 8:175-201

Treguier AM, Reynaud T, Pichevin T, Barnier B, Molines JM, de Miranda A, Messager C, Beismann JO, Madec G, Grima N, Imbard M, Le Provost C (1999) The CLIPPER project: High resolution modelling of the Atlantic. International WOCE newsletter, 36:3-5

Treguier AM, Barnier B, de Miranda A, Molines JM, Grima N, Imbard M, Madec G, Messager C, Michel S (2001) An eddy permitting model of the Atlantic circulation: evaluating open boundary conditions. J Geophys Res 106: 22115-22129

Treguier AM, Boebel O, Barnier B, Madec G (2003) Agulhas eddy fluxes in a 1/6 Atlantic model. Deep Sea Res II 50: 251-280

Trenberth KE, Olson JG, Large WG (1989) A global ocean wind stress climatology based on ECMWF analyses. National Center for Atmospheric research, Boulder, NCAR/TN-338+STR, 93 pp

Trenberth KE, Caron JM (2000). Estimates of meridional atmosphere and ocean heat transports. J of Climate 14: 3433-3443

Verron J, Le Provost C (1985) A numerical study of quasi-geostrophic flow over isolated topography. J Fluid Mech 154: 231-252

Verron J, Le Provost C, Holland WR (1987) On the Effects of a Midocean Ridge on the General Circulation: Numerical Simulations with an Eddy-Resolved Ocean Model. Journal of Physical Oceanography: 17: 301-312 
Webb D J, de Cuevas BA, Coward AC (1998) The first main run of the OCCAM global ocean model. Internal document No. 34, Southampton Oceanography Centre

Willebrand J, Barnier B, Böning C, Dieterich C, Killworth PD, Le Provost C, Jia Y, Molines JM, New AL (2001) Circulation characteristics in three eddy-permitting models of the North Atlantic. Progress in Oceanography 48: 123-162

Xie P, and Arkin PA (1997) Global Precipitation: A 17-Year monthly analysis based on gauge observations, satellite estimates, and numerical model outputs. Bull Amer Meteor Soc 78(11): 2539-2558 
Figure Legends

Figure 1. Domain decomposition on 186 processors of the DRAKKAR global $14^{\circ}$ ocean circulation model ORCAR025. Colours indicate the model bathymetry in metres. Every single box represents the domain accounted for by a processor. Boxes with a cross are 'land processors' not retained in the calculation. Numbers in abcissa and ordinate indicate model grid points.

Figure 2. Simulation G22 (partial step topography, new EEN vorticity scheme for momentum advection ): Snapshot of the sea surface height (ssh, in colour) and ice cover (in white) in Austral winter in year 10 of the simulation.

Figure 3. Meridonal overturning streamfunction (in Sv) averaged over year 8-10 of the G22 simulation (PS+EEN) for the Atlantic and b) the Indo-Pacific ocean basins. Contour interval is $2 \mathrm{~Sv}$.

Figure 4: Meridional heat transport (in Petawatts) averaged over year 8 to 10 of the G22 simulation for the Atlantic, Indo-Pacific and Global oceans. The advective MHT (red curve) is calculated using 5-day mean model meridional current velocities and temperatures. The surface flu x MHT (blue curve) is calculated as the meridional integration of surface fluxes. Differences between the curves indicate trends and storage. Black dots are estimates (with error bars) from an inversion of hydrographic data by Ganachaud and Wunsch (2003).

Figure 5: Global map of eddy kinetic energy (in $\mathrm{cm}^{2} \mathrm{~s}^{-2}$ ) in simulations G22 (3 year mean) and from satellite altimetry (Topex/Poseidon and ERS, Ducet et al., 2000).

Figure 6: Difference in the mean barotropic streamfunction (in Sv) between a) simulations G22 (PS+EEN) and G04 (FS+ENS) indicating where both the partial step topography and EEN scheme play a role, and b) between G03 (FS+EEN) and G04 (FS+ENS), both full step topography, indicating where advection scheme only has an impact. The red boxes identify the regions where model solution is compared to observation and other models. Colour palette indicates Sv. Axes are subdivided by grid point numbers.

Figure 7: Estimates of mean sea surface height $(m s s h$ in $\mathrm{cm}$ ) in the North Atlantic from a) Observations (Niiler et al., 2003), b) global ORCA-R025 model simulation G22 (PS+EEN), c) global OCCAM model simulation, d) global ORCA-R025 model simulation G04 (FS+ENS), e) global POP1/10 and f) Atlantic CLIPPER ATL6 model simulation. All model results present a 3 year mean. To remove mean biases between estimates, the area mean has been subtracted for each plot, and thus grey (white) areas indicate region of mssh higher (lower) than the area mean. Contour interval is $10 \mathrm{~cm}$.

Figure 8: Estimates of the mean eddy kinetic energy $\left(e k e\right.$ in $\left.\mathrm{cm}^{2} \mathrm{~s}^{-2}\right)$ in the North Atlantic from a) Observations (Niiler et al., 2003), b) global ORCA-R025 model simulation G22 (PS+EEN), c) global OCCAM model simulation, d) global ORCA-R025 model simulation G04 (FS+ENS), e) global POP1/10 and f) Atlantic CLIPPER ATL6 model simulation. All model results present a 3 year mean.

Figure 9: Same as Figure 7 (plots of $m s s h$ in $\mathrm{cm}$ ) for the western South Atlantic. Contour interval is $10 \mathrm{~cm}$. 
Figure 10: Same as Figure 8 (plots of $e k e$ in $\mathrm{cm}^{2} \mathrm{~s}^{-2}$ ) for the western South Atlantic.

Figure 11: Snapshot of current speed (in $\mathrm{m} / \mathrm{s}$ ) at $25 \mathrm{~m}$ depth in the Cape Basin and the region of the retroflection of the Agulhas Current for a) simulation ORCA-R025 G22 (PS+EEN) and b) simulation ORCA -R025 G04 (PS+ENS).

Figure 12: Same as Figure 8 (plots of $e k e$ in $\mathrm{cm}^{2} \mathrm{~s}^{-2}$ ) for the Cape Basin in the South Atlantic.

Figure 13: Same as in Fig. 7 (plots of $m s s h$ in $\mathrm{cm}$ ) for the western Pacific (without the CLIPPER model which only covers the Atlantic). Contour interval is $10 \mathrm{~cm}$.

Figure 14: Estimates of mean sea surface height ( $m s s h$ in $\mathrm{cm}$ ) in the South Indian Ocean from (top) observations (Niiler et al., 2003), (middle) global ORCA-R025 model simulation G22 (PS+EEN), and (bottom) global ORCAR025 model simulation G04 (FS+ENS). All modelresults present a 3 year mean. Mean biases between estimates have been removed by subtracting the area mean for each plot. Thus grey (white) areas indicate region of $m s h$ higher (lower) than the area mean. Contour interval is $10 \mathrm{~cm}$. The bold dashed lines indicate the location of the main topographic features of the South Indian Ridge, as reported in the topography map of Figure 15.

Figure 15: Same as in Fig. 8 (plots of $e k e$ in $\mathrm{cm}^{2} \mathrm{~s}^{-2}$ ) for the South Indian Ocean (without the Clipper model which only covers the Atlantic). The bottom topography of the area is shown (bottom right plot), with a contour interval of $500 \mathrm{~m}$. The bold dashed lines indicate the location of the main topographic features of the South Indian Ridge.

Figure 16. Bottom topography (in metres) of the South Pacific around New Zealand. Colours indicate the depth. Contour interval is $500 \mathrm{~m}$.

Figure 17: Same as in Fig. 7 (plots of $m s s h$ in $\mathrm{cm}$ ) for the Campbell Plateau in the South Pacific (without the Clipper model which only covers the Atlantic). Contour interval is $10 \mathrm{~cm}$.

Figure 18 : Snapshot of the normalized grid-scale irregularities in vertical velocity fields as a function of the level above the bottom $(k u p)$, averaged over the Gulf Stream area, in simulations G04 $(F S+E N S)$, G03 $(F S+E E N)$, and $\mathrm{G} 22(P S+E E N)$. The difference $(\delta w)$ between the vertical velocity $(w)$ and its 9 cell-average $(\bar{w})$ has been computed on each model level. The vertical levels have been re-indexed from the bottom $\left(k u p=i\right.$ is the $i^{\text {th }}$ level above the bottom). The grid-scale irregularity which is plotted is the ratio between the averages at constant kup of $|\delta w|$ and $|\bar{w}|$. 


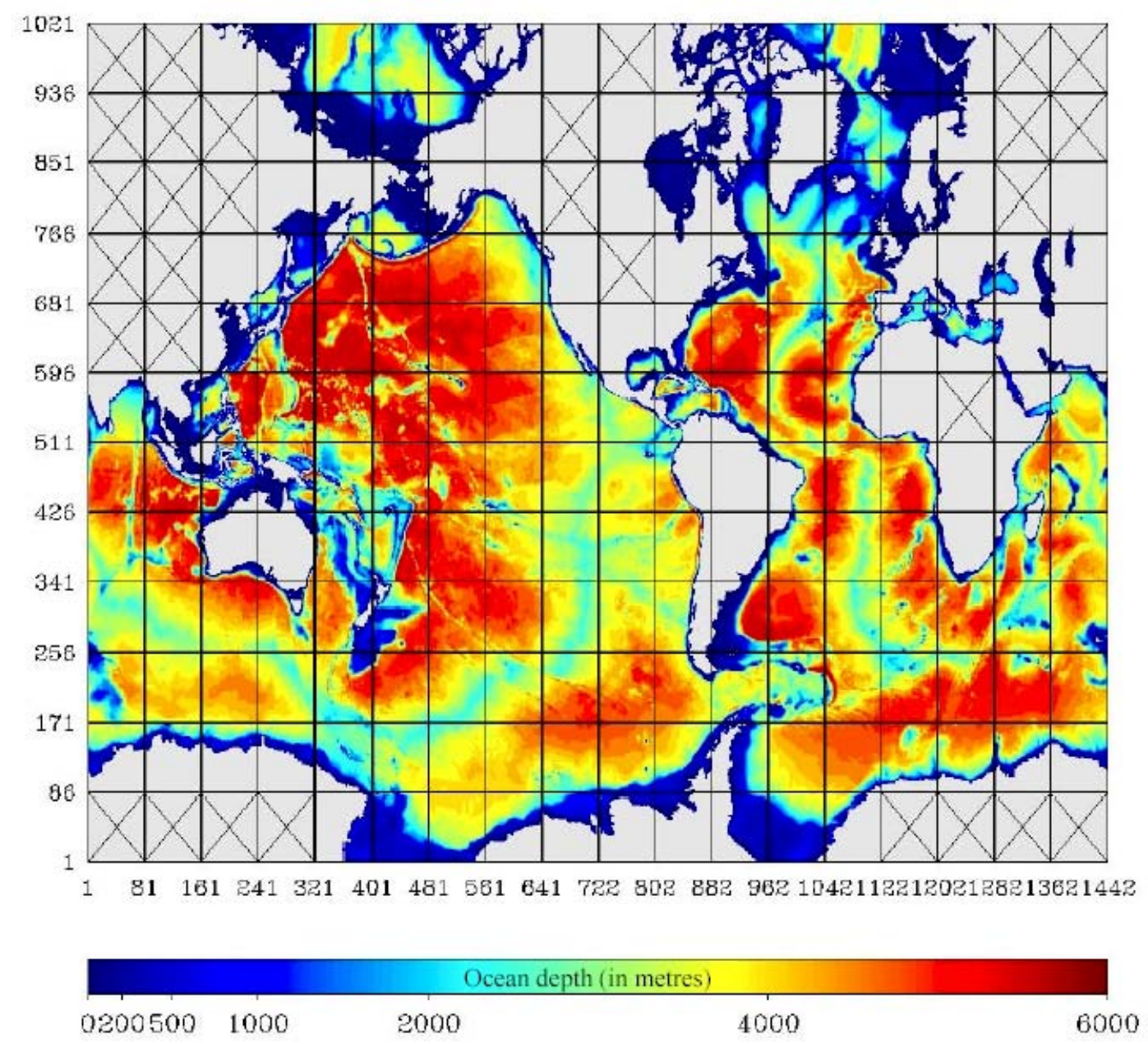

Figure 1. Domain decomposition on 186 processors of the DRAKKAR global $14^{\circ}$ ocean circulation model ORCAR025. Colours indicate the model bathymetry in metres. Every single box represents the domain accounted for by a processor. Boxes with a cross are 'land processors' not retained in the calculation. Numbers in abcissa and ordinate indicate model grid points. 


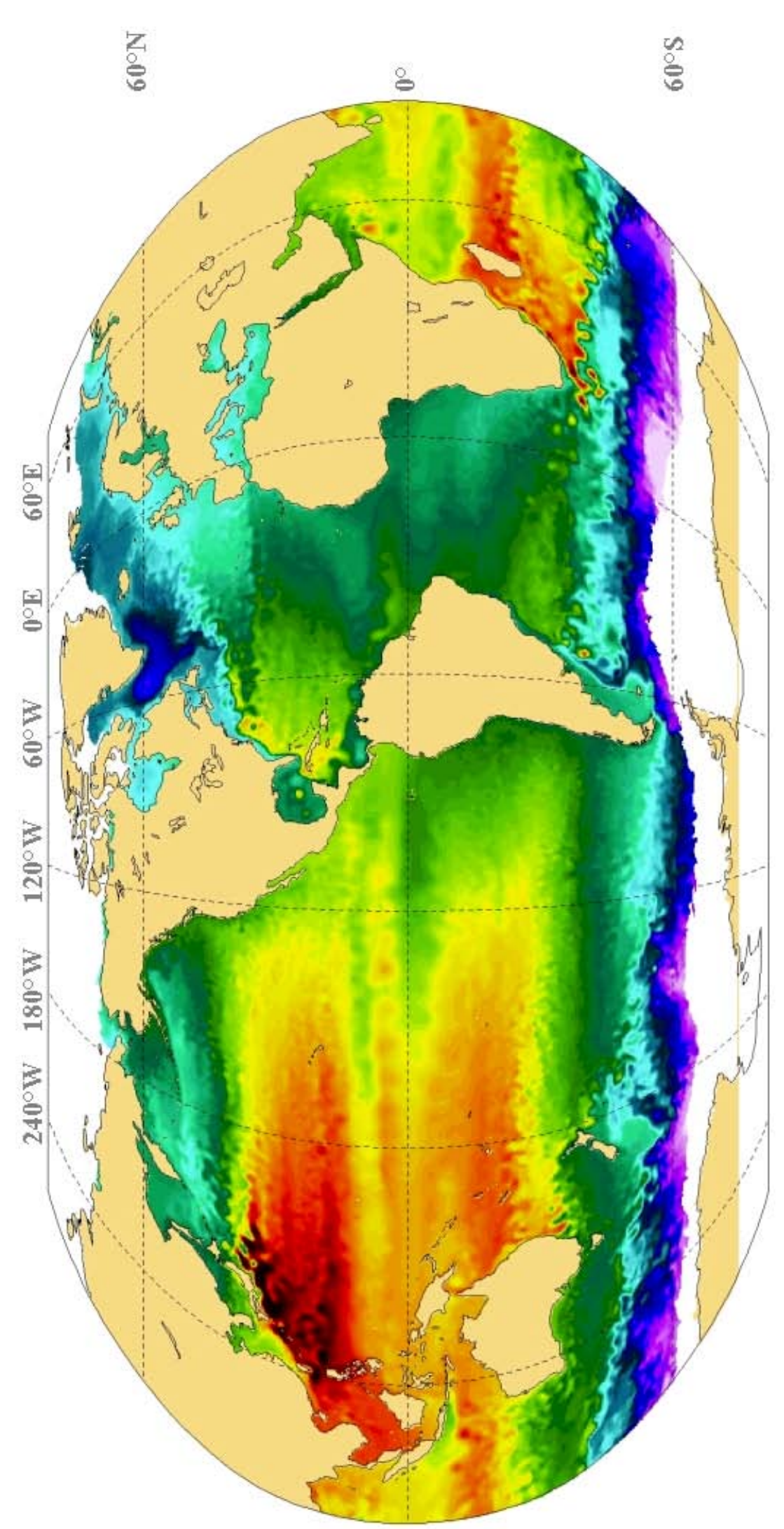

롤

$\left[\begin{array}{l}0 \\ - \\ \\ 0 \\ 10 \\ 0\end{array}\right.$

8

10

0

S

i

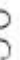

?

।

8

N

Figure 2. Simulation G22 (partial step topography, new EEN vorticity scheme for momentum advection): Snapshot of the sea surface height (ssh, in colour) and ice cover (in white) in Austral winter in year 10 of the simulation. 


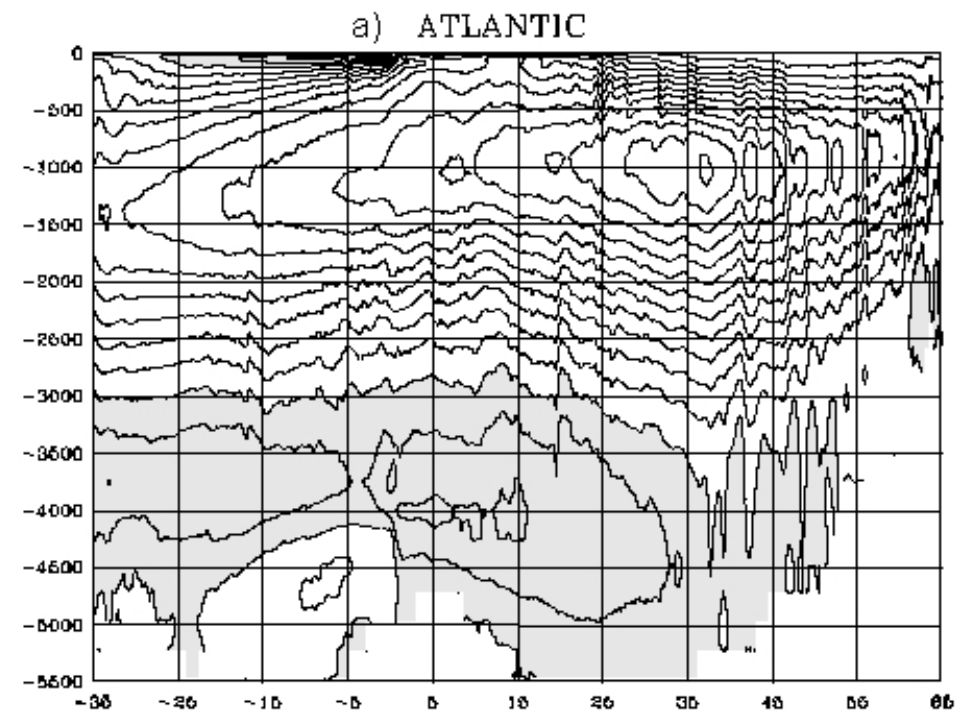

b) INDO-PAC

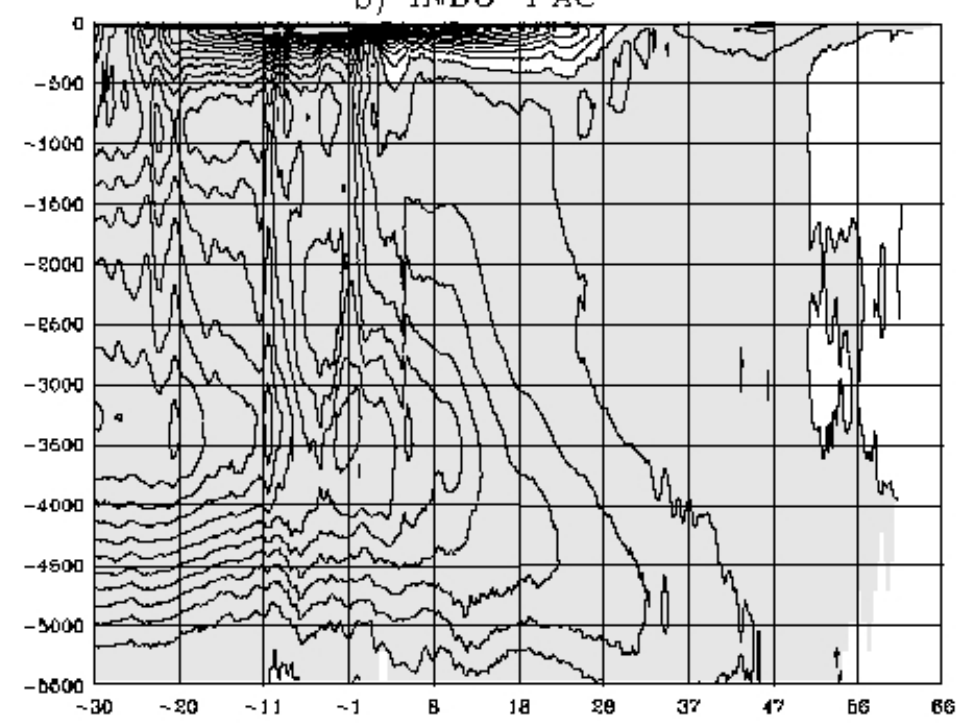

Figure 3. Meridonal overturning streamfunction averaged over year 8-10 of the G22 simulation (PS+EEN) for the Atlantic and b) the Indo-Pacific ocean basins. Contour interval is $2 \mathrm{~Sv}$. 

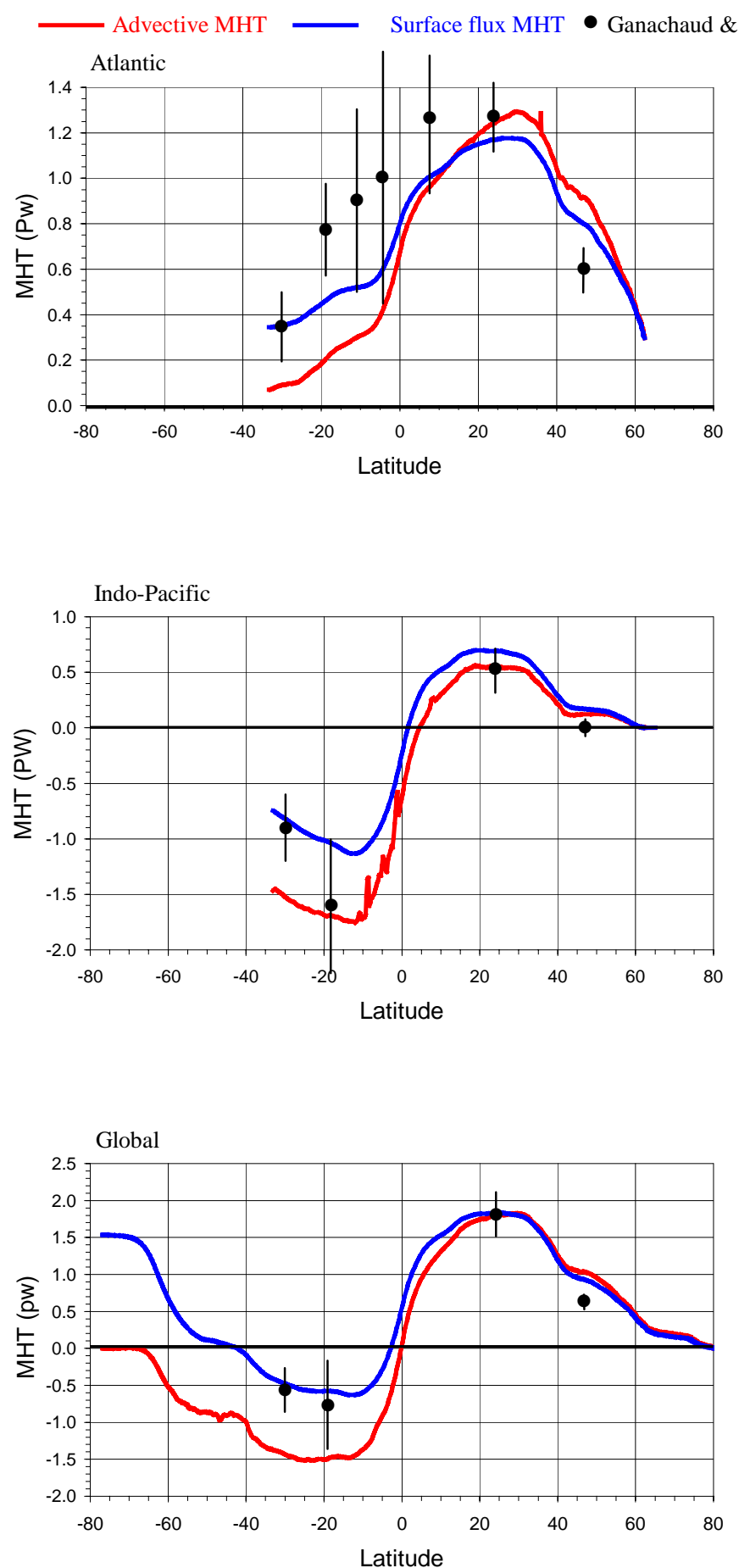

Figure 4: Meridional heat transport (in Petawatts) averaged over year 8-10 of the G22 simulation for the Atlantic, Indo-Pacific and Global oceans. The advective MHT (red curve) is calculated using 5-day mean model meridional current velocities and temperatures. The surface flux MHT (blue curve) is calculated from the divergence of the surface flux. Differences between the curves indicate trends and storage. Black dots are estimates (with error bars) from an inversion of hydrographic data by Ganachaud and Wunsch (2003). 


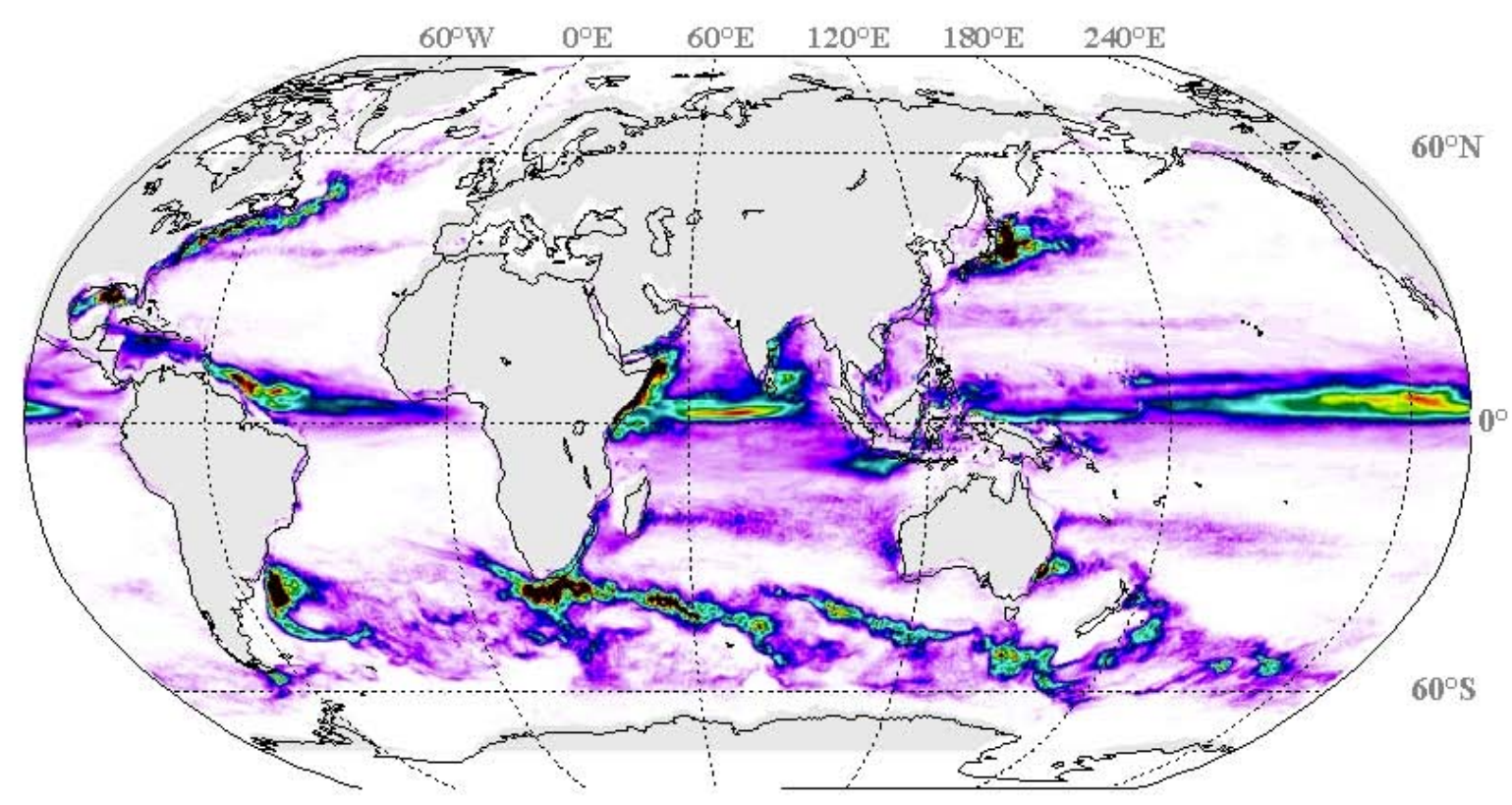

a) EKE in simulation G22

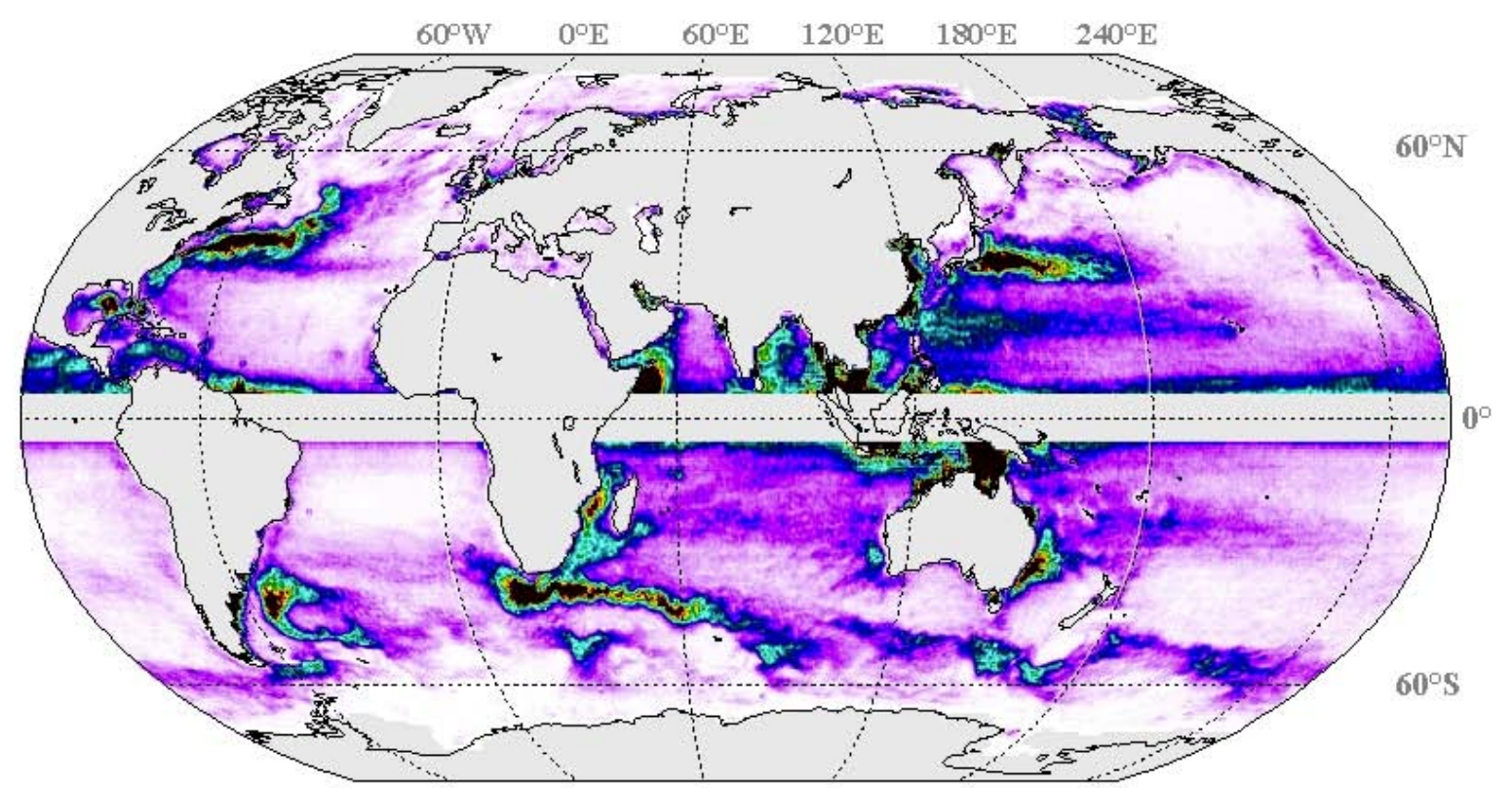

b) EKE from satellite atlimetry

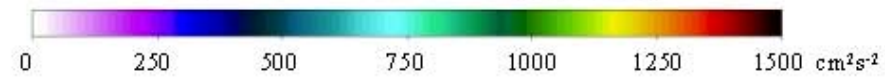

Figure 5: . Global map of eddy kinetic energy (in $\left.\mathrm{cm}^{2} \mathrm{~s}^{-2}\right)$ in simulations G22 (3 year mean) and from satellite altimetry (Topex/Poseidon and ERS, Ducet et al., 2000). 
a) $B S F$ difference between simulations $\mathrm{G} 22$ and G04

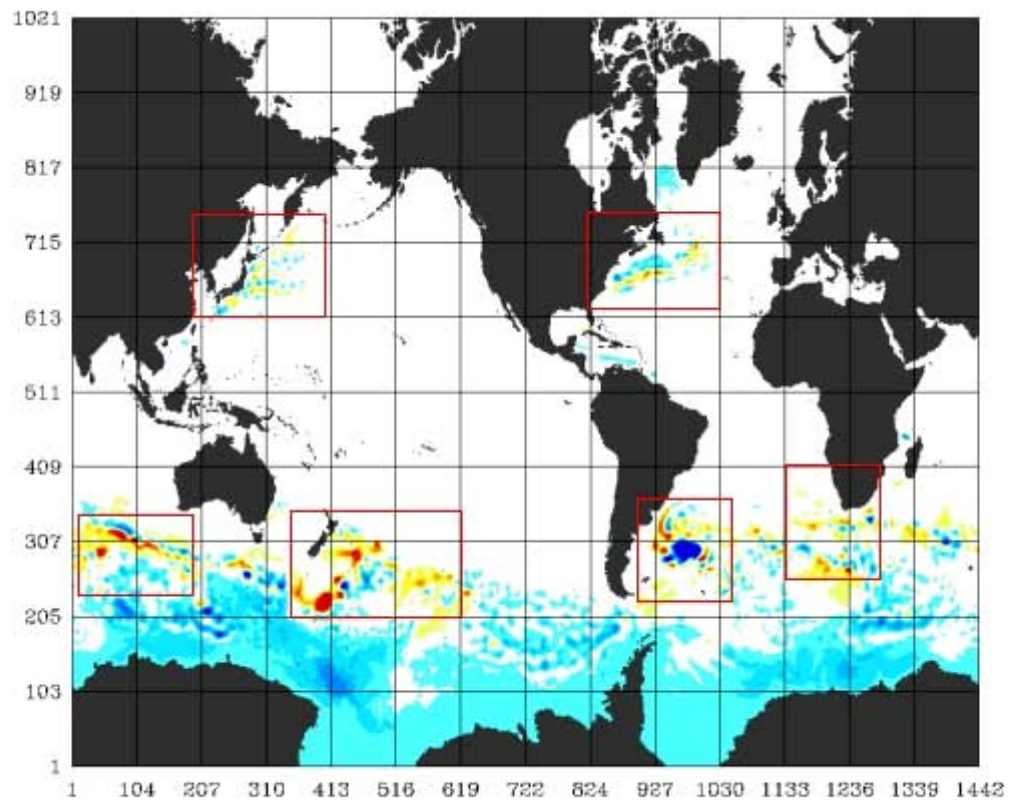

b) $B S F$ difference between simulations $\mathrm{G} 03$ and $\mathrm{G} 04$
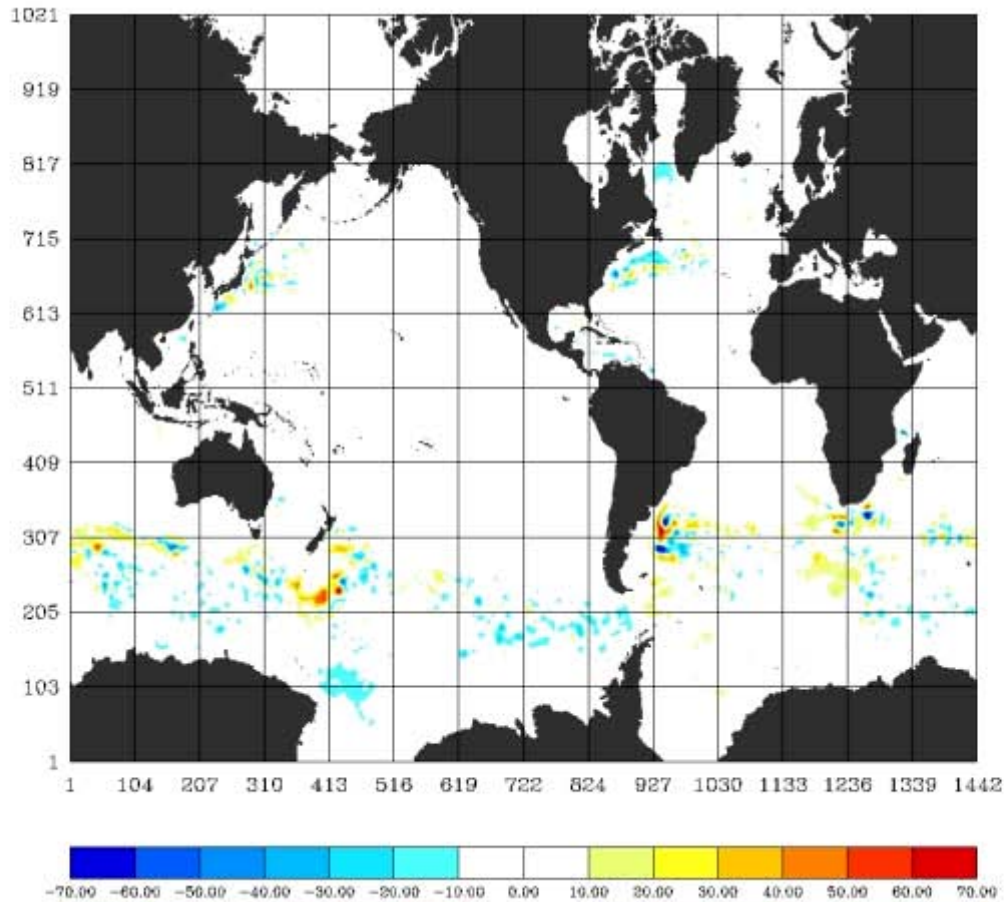

Figure 6: Difference in the mean barotropic streamfunction (in Sv) between a) simulations G22 (PS+EEN) and G04 (FS+ENS) indicating where both the partial step topography and EEN scheme play a role, and b) between G03 (FS+EEN) and G04 (FS+ENS), both full step topography, indicating where advection scheme only has an impact. The red boxes identify the regions where model solution is compared to observation and other models. Colour palette indicates Sv. Axes are subdivided by grid point numbers. 
a) NHLER

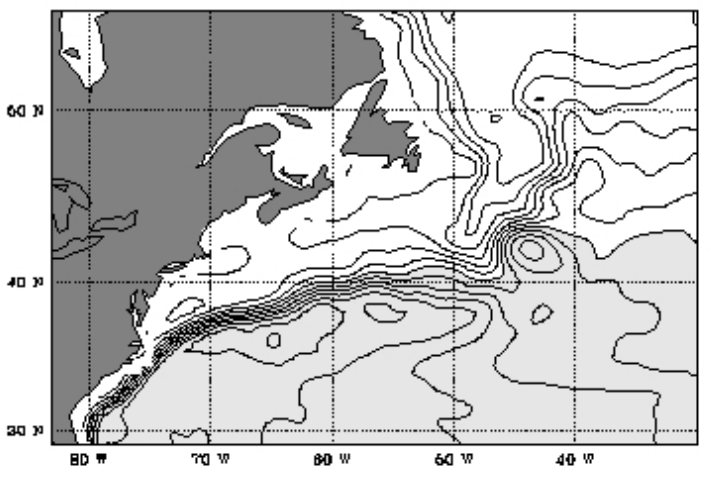

c) OCCAM

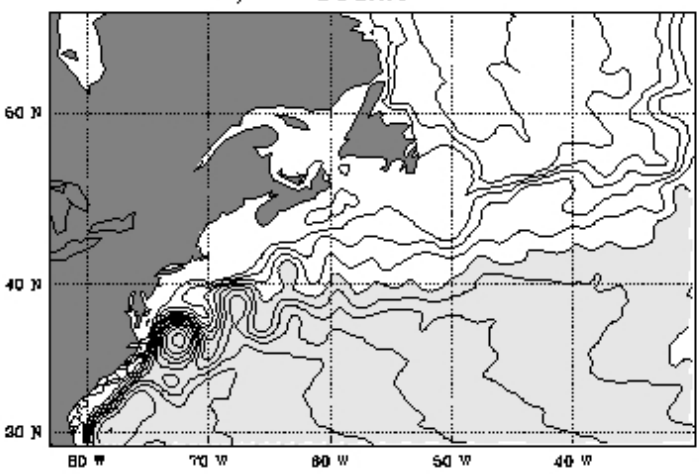

e) $\operatorname{POP} 1 / 10$

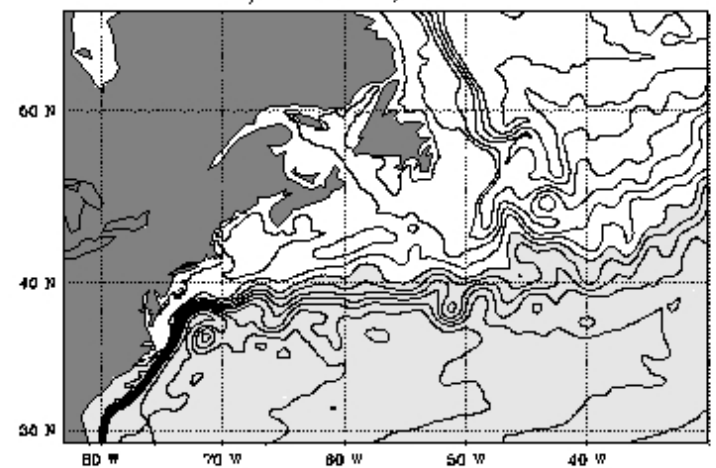

b) ORCA025-G22

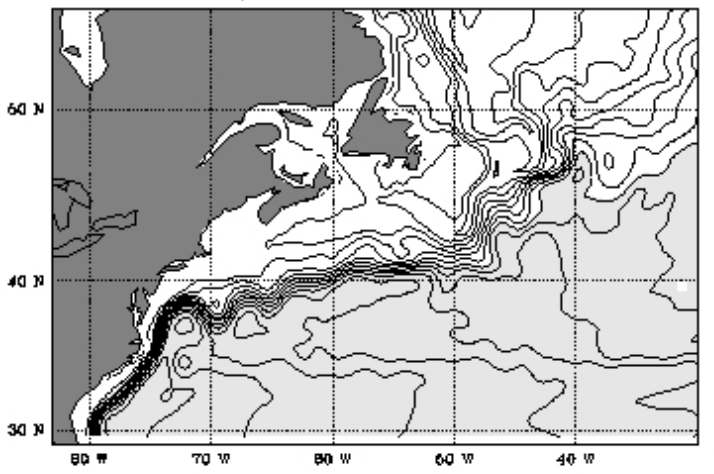

d) ORCA025-G04

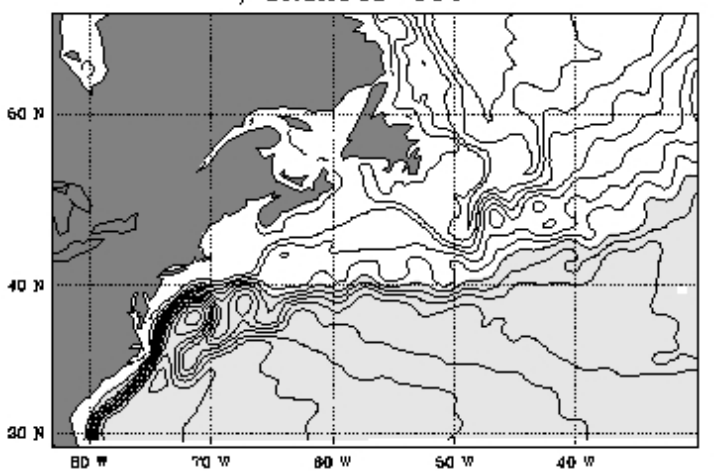

f) CLIPPER ATL6

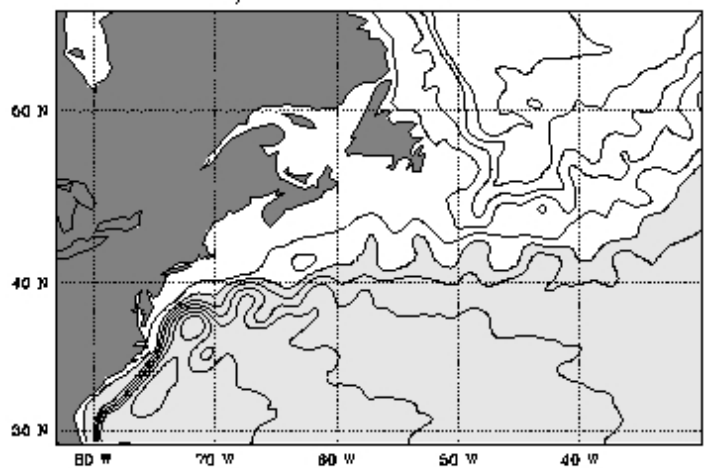

Figure 7: Estimates of mean sea surface height $(m s s h$ in $\mathrm{cm}$ ) in the North Atlantic from a) Observations (Niiler et al., 2003), b) global ORCA-R025 model simulation G22 (PS+EEN), c) global OCCAM model simulation, d) global ORCA-R025 model simulation G04 (FS+ENS), e) global POP1/10 and f) Atlantic CLIPPER ATL6 model simulation. All model results present a 3 year mean. To remove mean biases between estimates, the area mean has been subtracted for each plot, and thus grey (white) areas indicate region of $m s s h$ higher (lower) than the area mean. Contour interval is $10 \mathrm{~cm}$. 
a) Altimetry $\mathrm{T} / \mathrm{P}+\mathrm{ERS}$

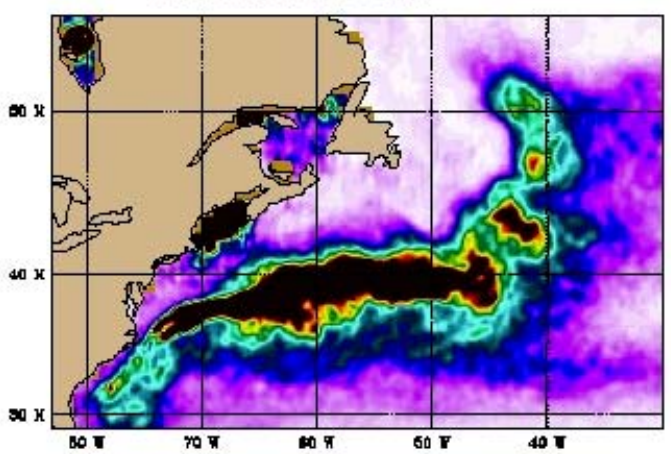

c) OCCAM

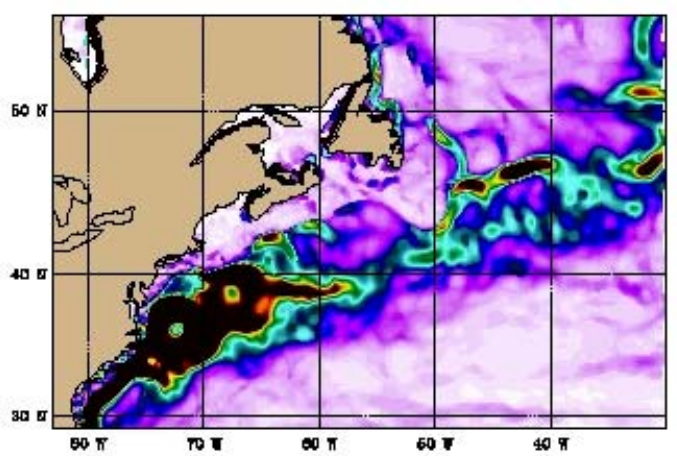

e) POPl 10

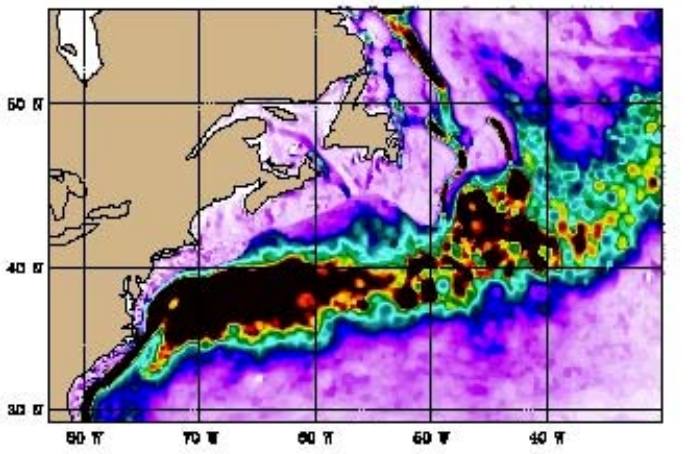

b) ORCA-R025 G22

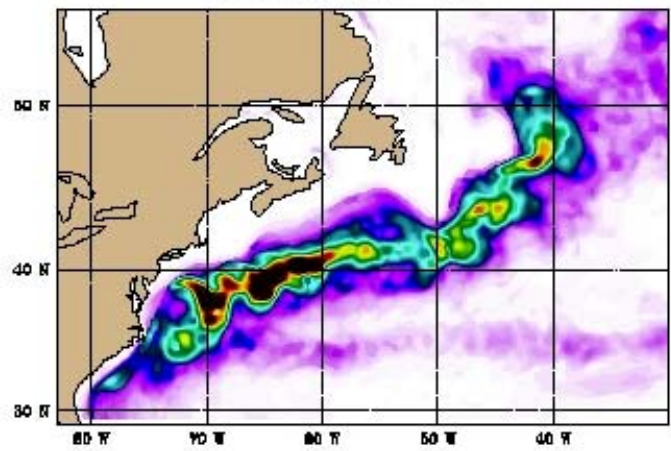

d) ORCA-R025 G04

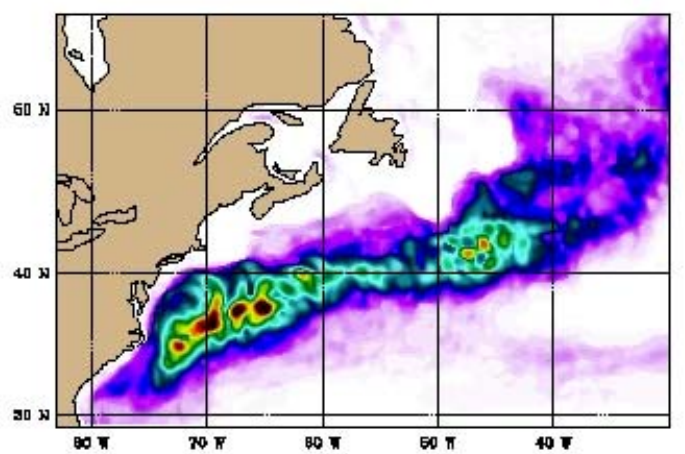

f) CLIPPER ATL6

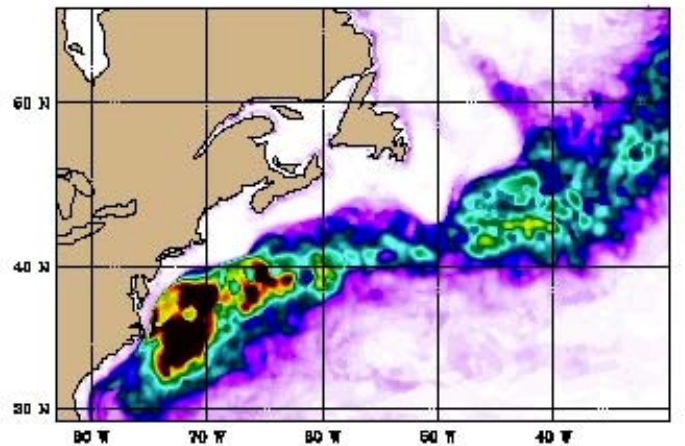

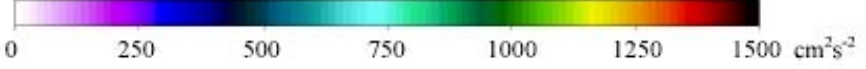

Figure 8: Estimates of the mean eddy kinetic energy $\left(e k e\right.$ in $\left.\mathrm{cm}^{2} \mathrm{~s}^{-2}\right)$ in the North Atlantic from a) Observations (Niiler et al., 2003), b) global ORCA-R025 model simulation G22 (PS+EEN), c) global OCCAM model simulation, d) global ORCA-R025 model simulation G04 (FS+ENS), e) global POP1/10 and f) Atlantic CLIPPER ATL6 model simulation. All model results present a 3 year mean. 

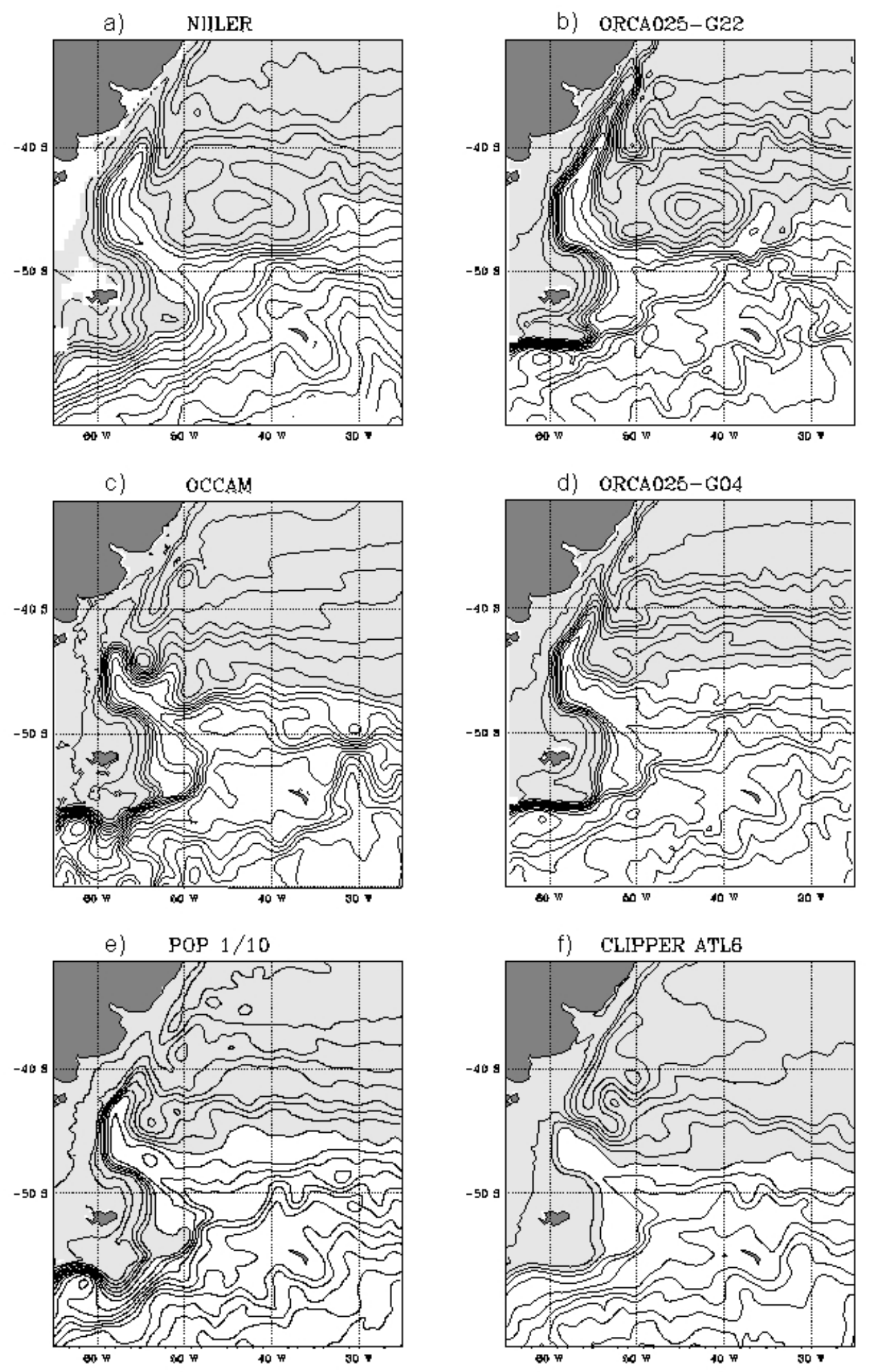

Figure 9: Same as Figure 7 (plots of $m s s h$ in $\mathrm{cm}$ ) for the western South Atlantic. Contour interval is $10 \mathrm{~cm}$. 
a) Altimetry $T / P+E R S$

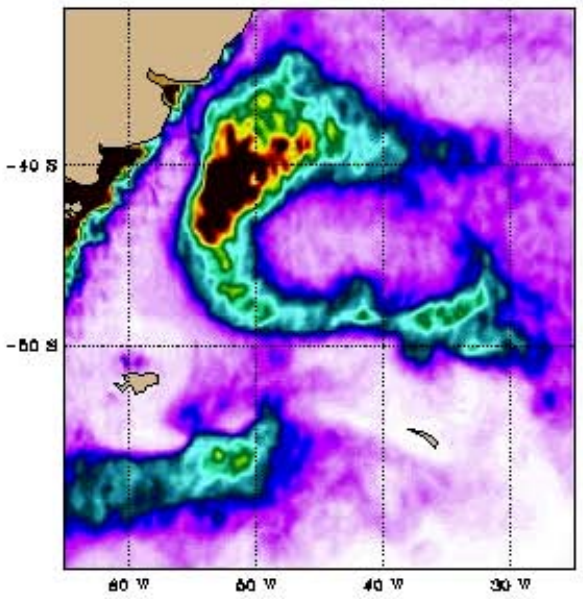

c) OCCAM

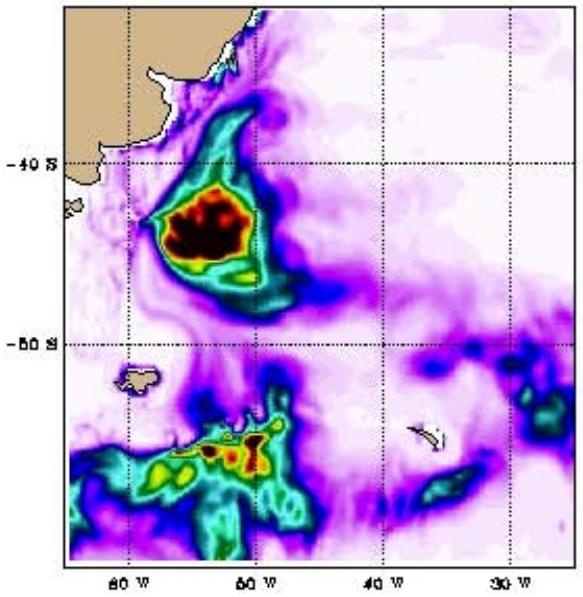

e) $\mathrm{POP} 1 / 10$

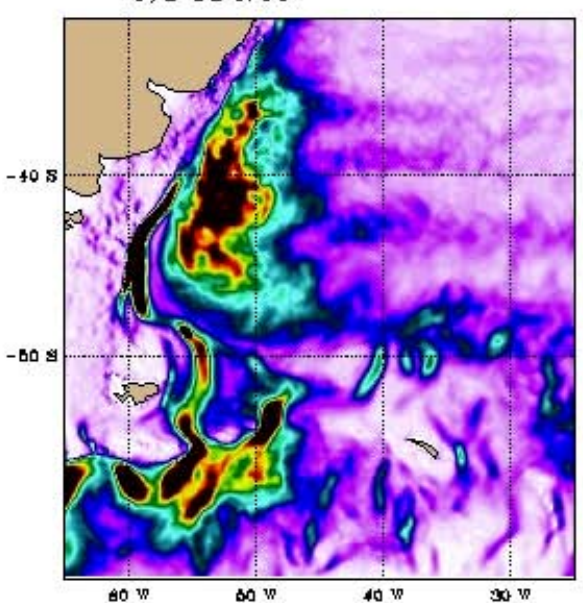

b) ORCA-R025 G22

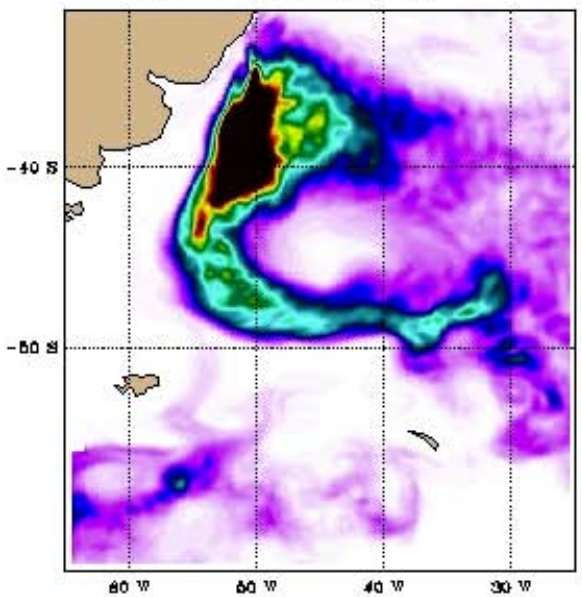

d) ORCA-R025 G04

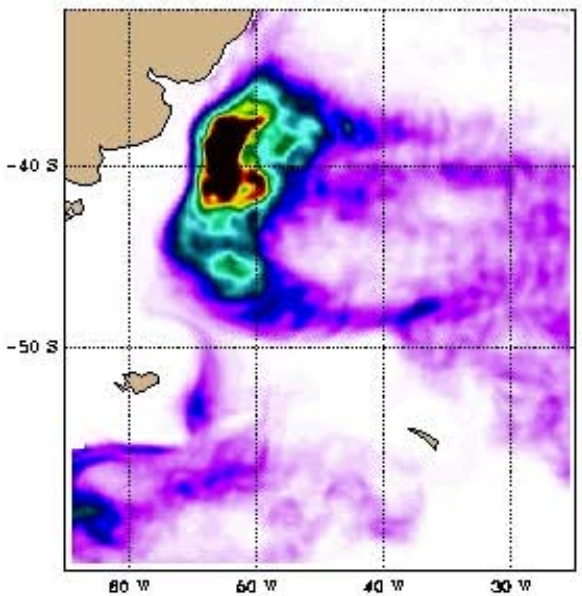

f) CLIPPER ATL6

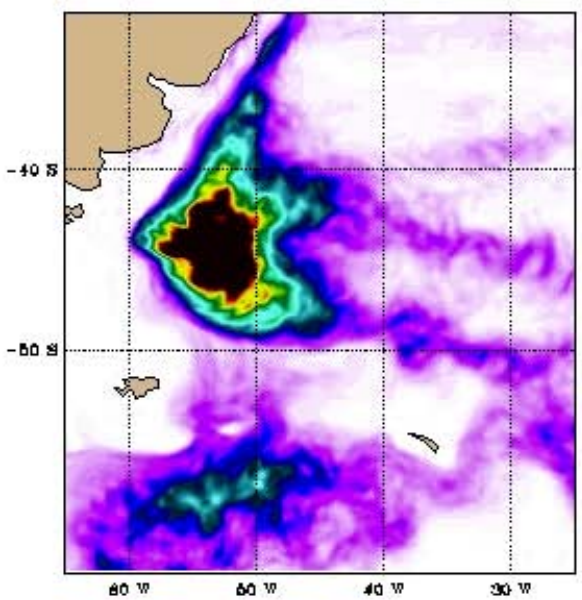

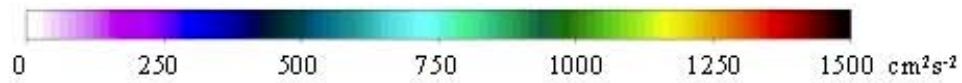

Figure 10: Same as Figure 8 (plots of $e k e$ in $\mathrm{cm}^{2} \mathrm{~s}^{-2}$ ) for the western South Atlantic. 


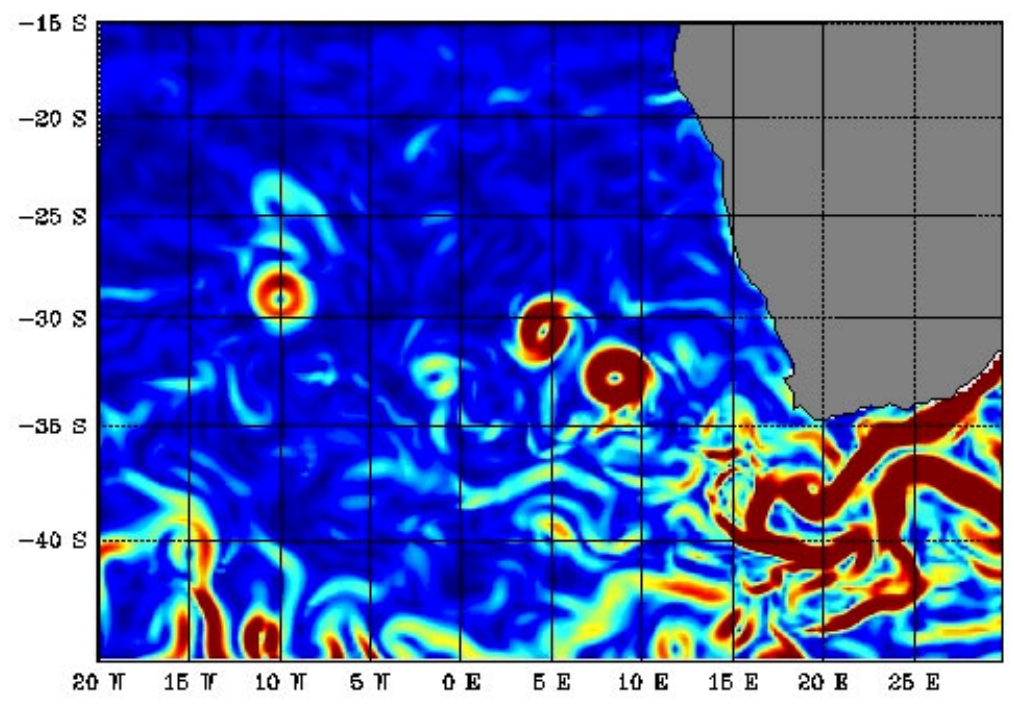

a) Simulation G22 (PS and EEN advection)

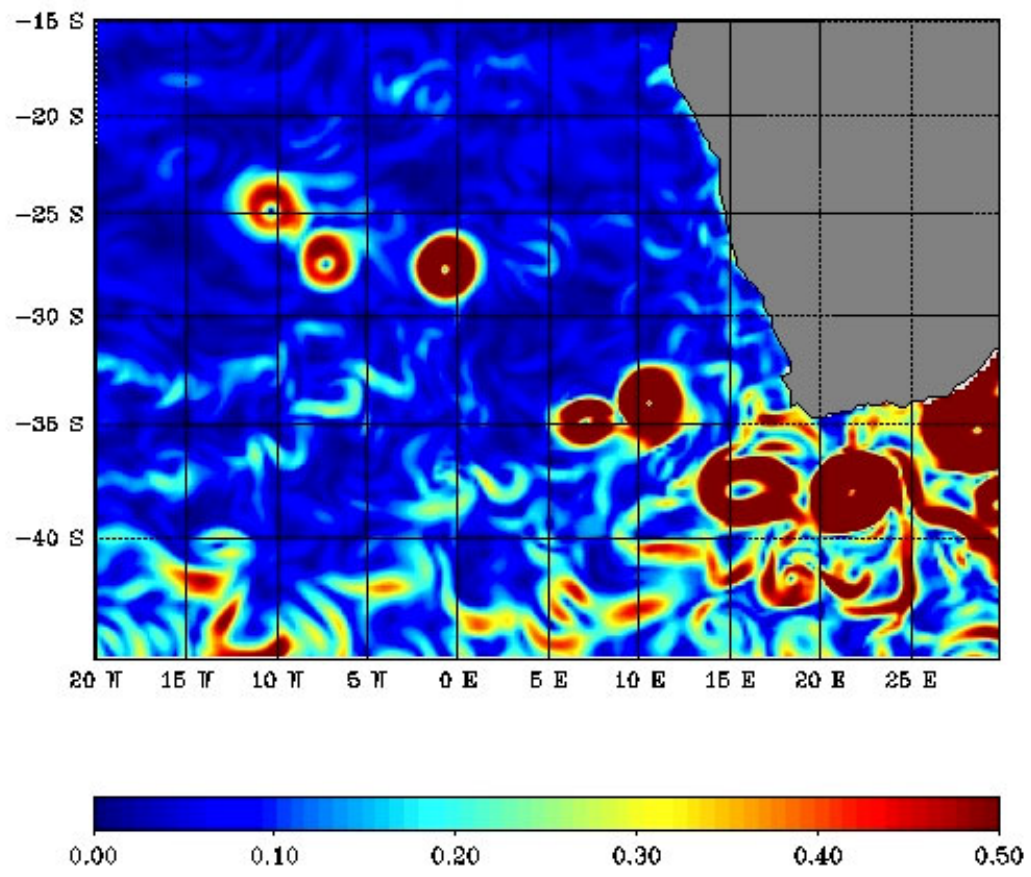

b) Simulation G04 (FS and ENS advection)

Figure 11: Snapshot of current speed (in $\mathrm{m} / \mathrm{s}$ ) at $25 \mathrm{~m}$ depth in the Cape Basin and the region of the retroflection of the Agulhas Current for a) simulation ORCA-R025 G22 (PS+EEN) and b) simulation ORCA-R025 G04 (PS+ENS). 
a) Altimetry T/P+ERS

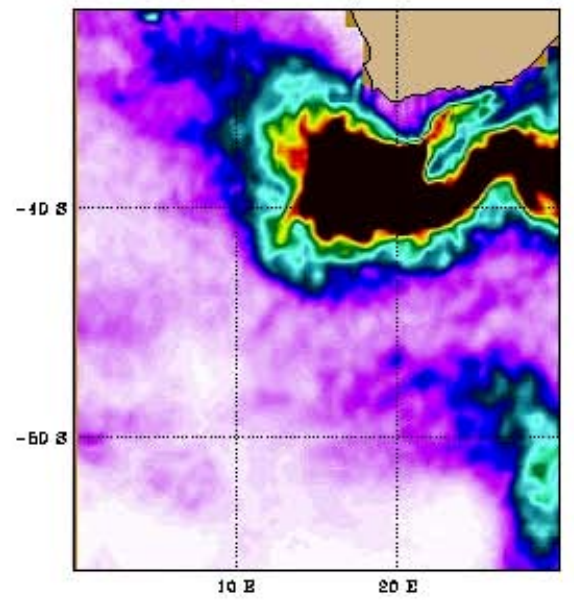

c) OCCAM

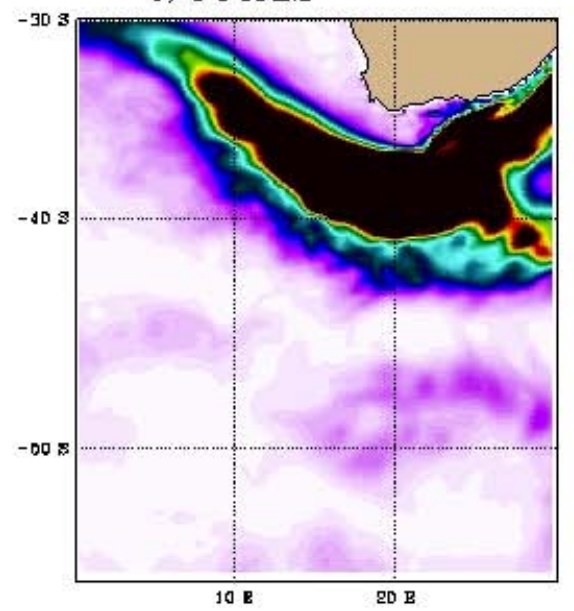

e) POP $1 / 10$

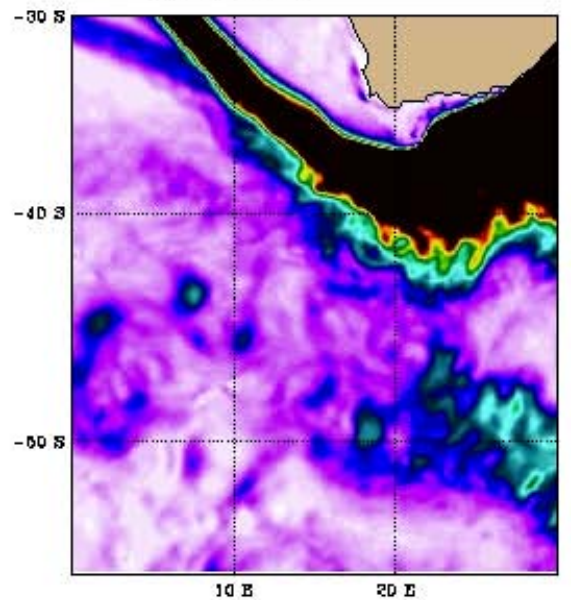

b) ORCA-R025 G22

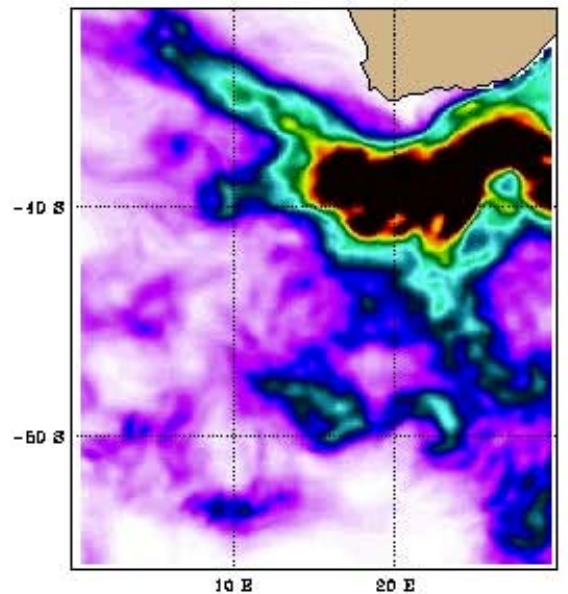

d) ORCA-R025 G04

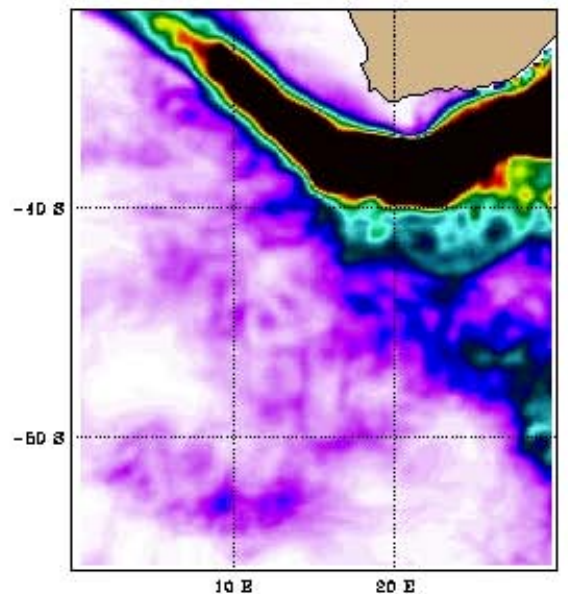

f) CLIPPER ATL6

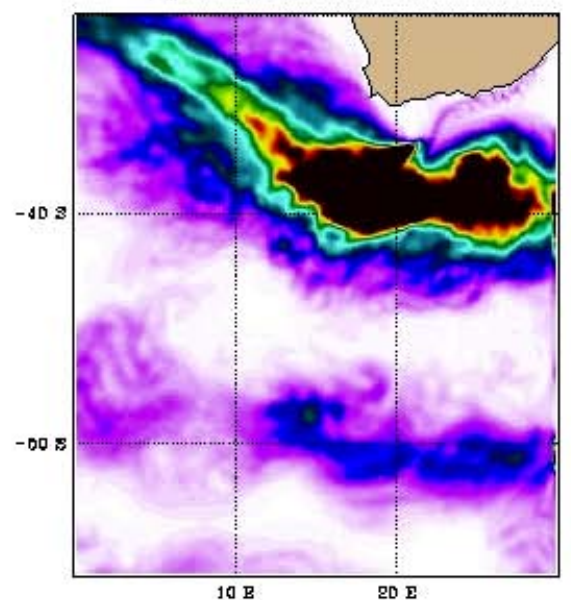

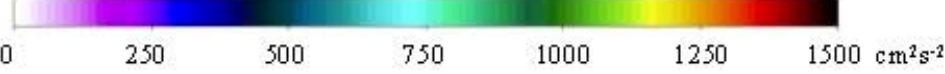

Figure 12: Same as Figure 8 (plots of $e k e$ in $\mathrm{cm}^{2} \mathrm{~s}^{-2}$ ) for the Cape Basin in the South Atlantic. 

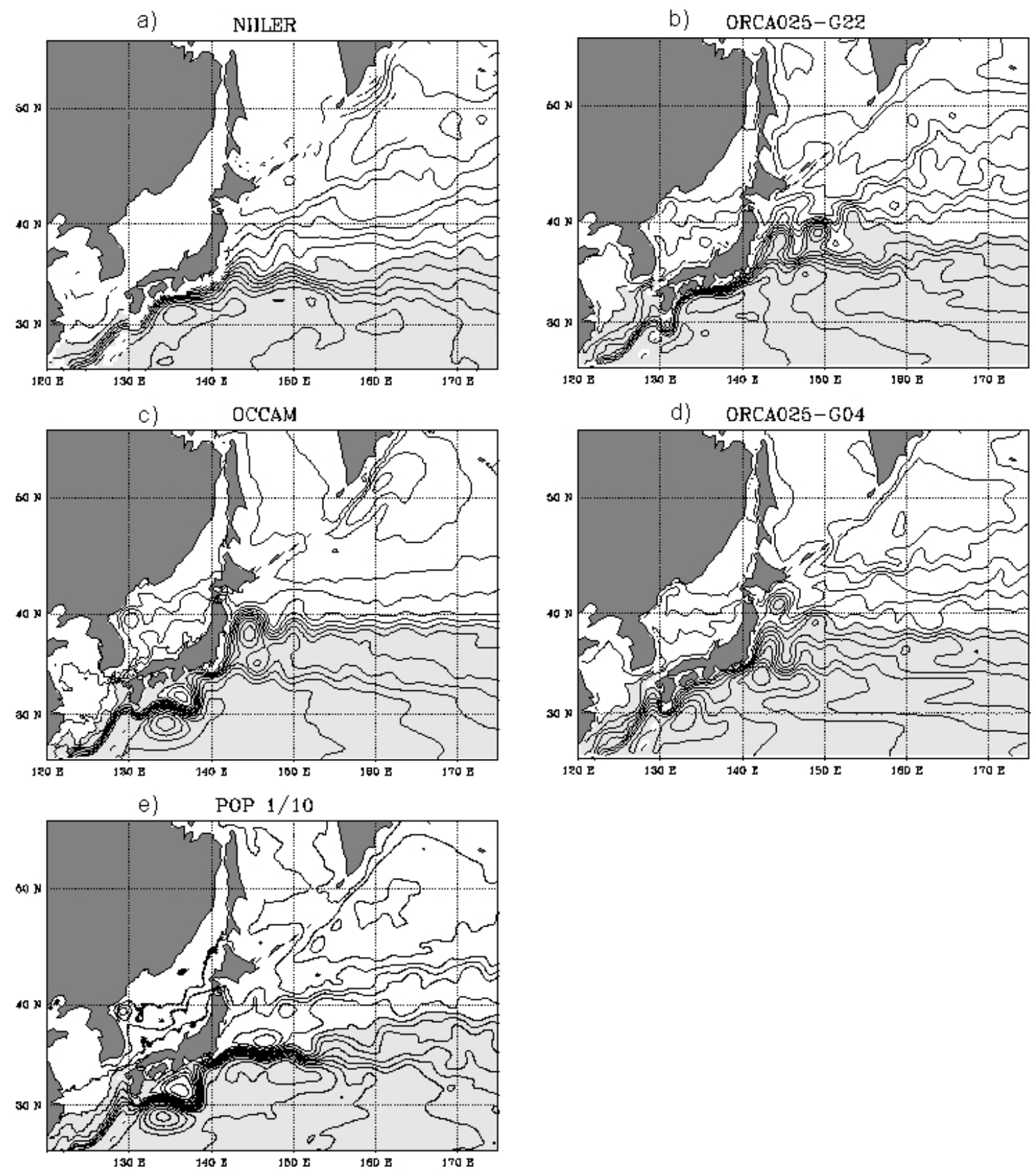

Figure 13: Same as in Fig. 7 (plots of $m s s h$ in $\mathrm{cm}$ ) for the western Pacific (without the CLIPPER model which only covers the Atlantic). Contour interval is $10 \mathrm{~cm}$. 

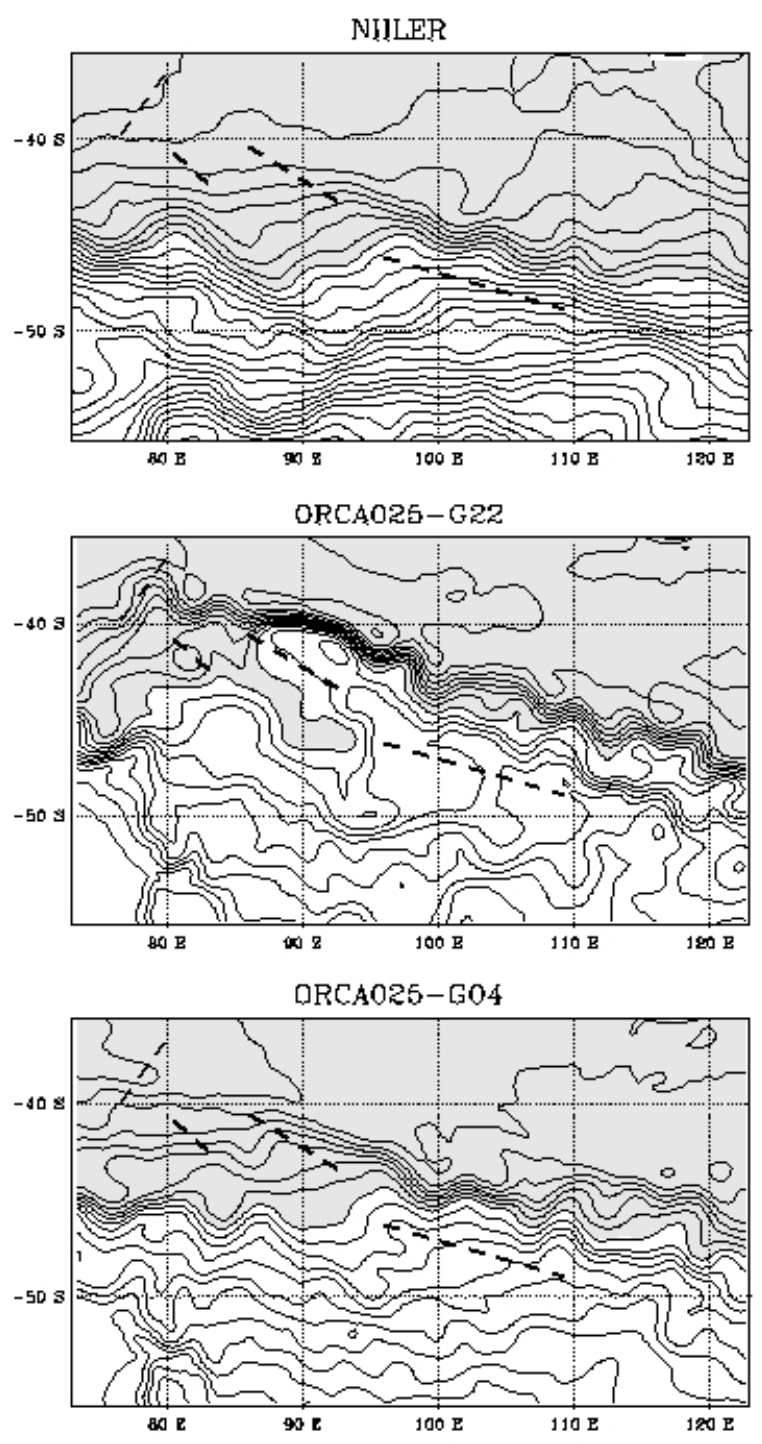

Figure 14: Estimates of mean sea surface height $(m s s h$ in $\mathrm{cm}$ ) in the South Indian Ocean from (top) observations (Niiler et al., 2003), (middle) global ORCA-R025 model simulation G22 (PS+EEN), and (bottom) global ORCAR025 model simulation G04 (FS+ENS). All model results present a 3 year mean. Mean biases between estimates have been removed by subtracting the area mean for each plot. Thus grey (white) areas indicate region of $m s s h$ higher (lower) than the area mean. Contour interval is $10 \mathrm{~cm}$. The bold dashed lines indicate the location of the main topographic features of the South Indian Ridge, as reported in the topography map of Figure 15. 
a) Altimetry $T / P+E R S$

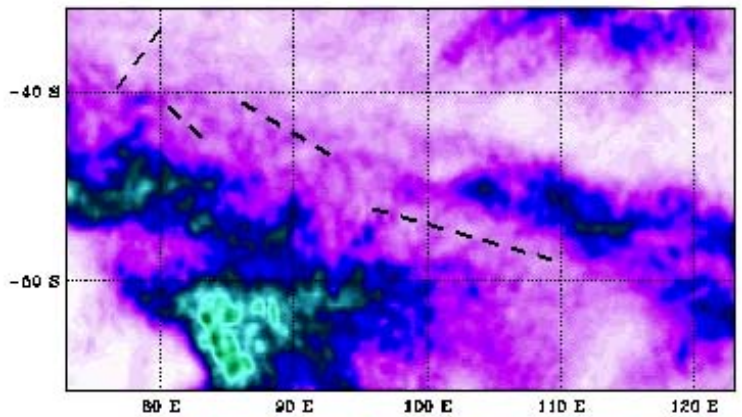

c) OCCAM

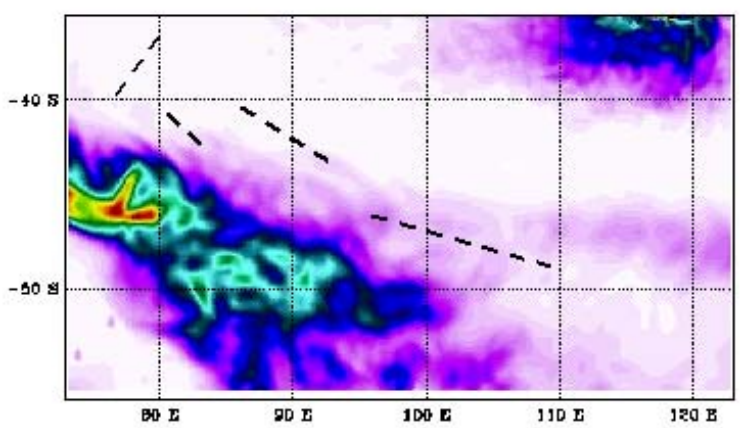

e) $P O P 1 / 10$

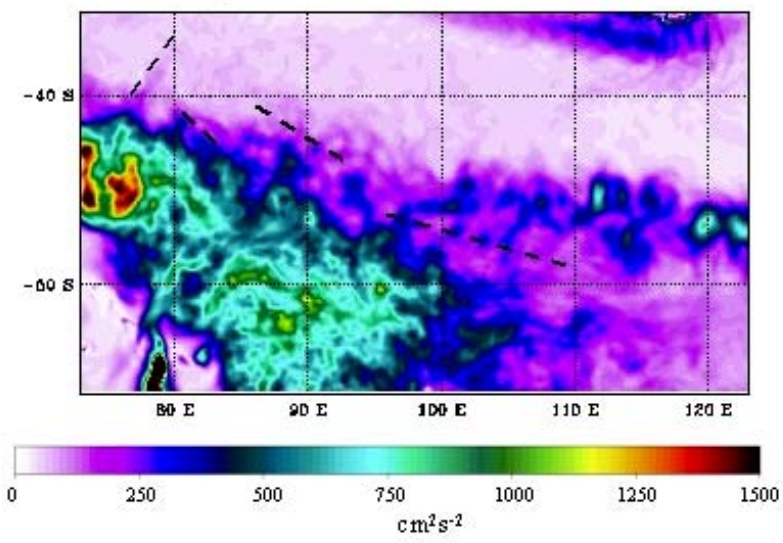

b) ORCA-R025 G22

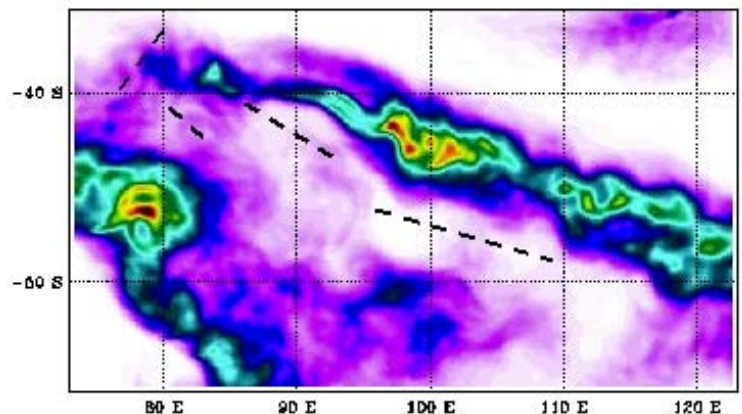

d) ORCA-R025 G04

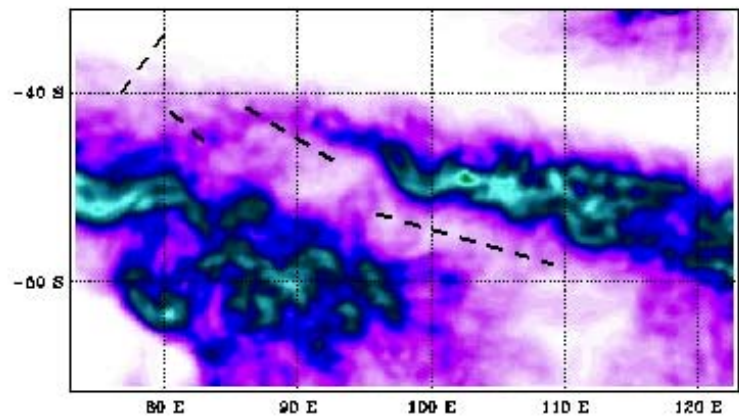

f) Bottom topography

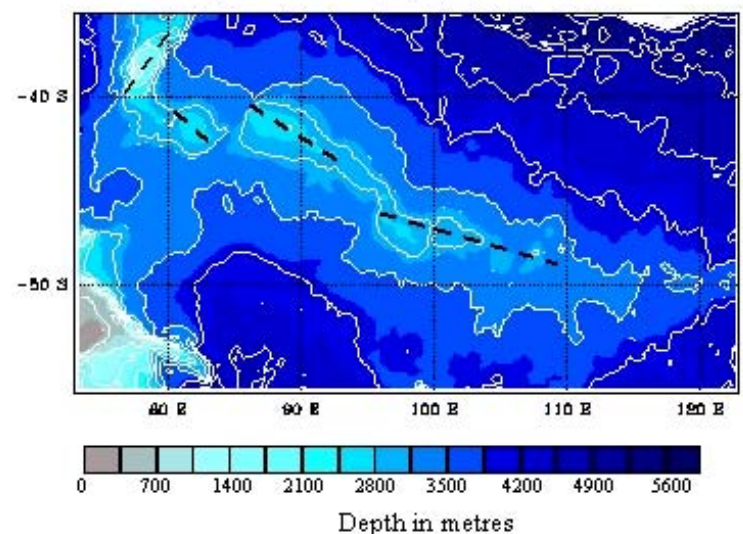

Figure 15: Same as in Fig. 8 (plots of $e k e$ in $\mathrm{cm}^{2} \mathrm{~s}^{-2}$ ) for the South Indian Ocean (without the Clipper model which only covers the Atlantic). The bottom topography of the area is shown (bottom right plot), with a contour interval of $500 \mathrm{~m}$. The bold dashed lines indicate the location of the main topographic features of the South Indian Ridge. 


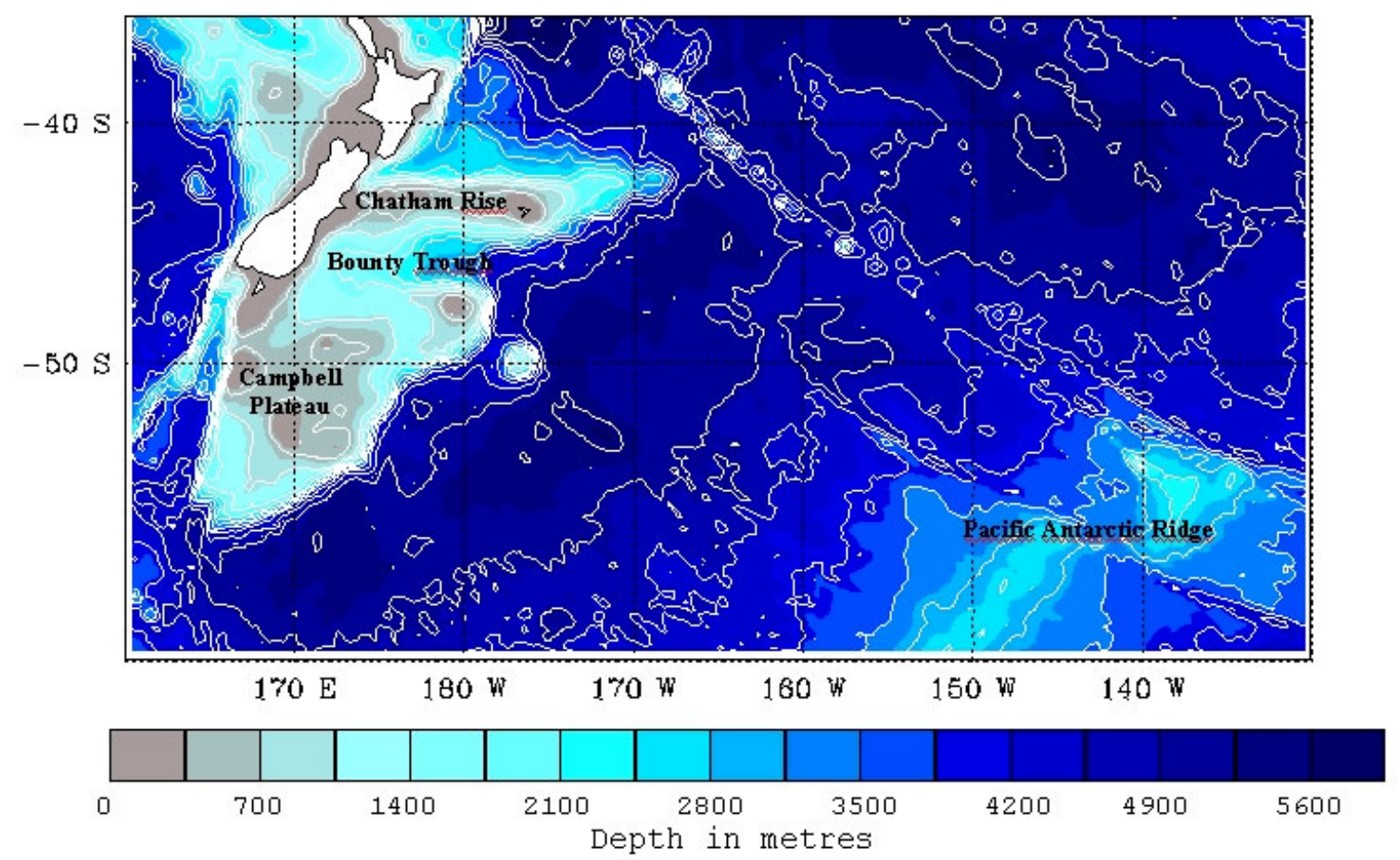

Figure 16. Bottom topography (in metres) of the South Pacific around New Zealand. Colours indicate the depth. Contour interval is $500 \mathrm{~m}$. 
a)

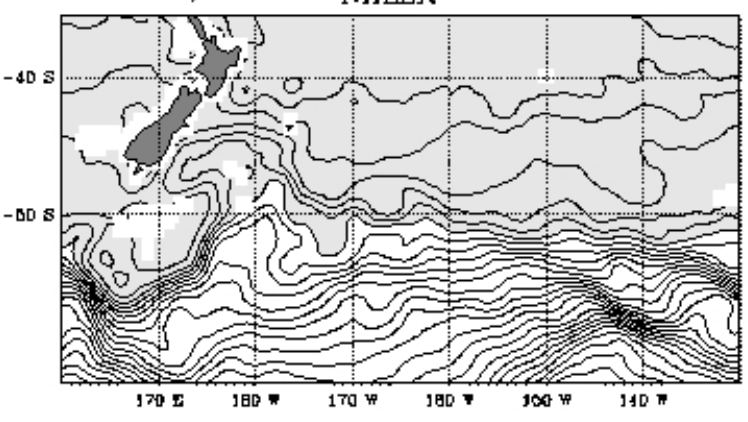

c)

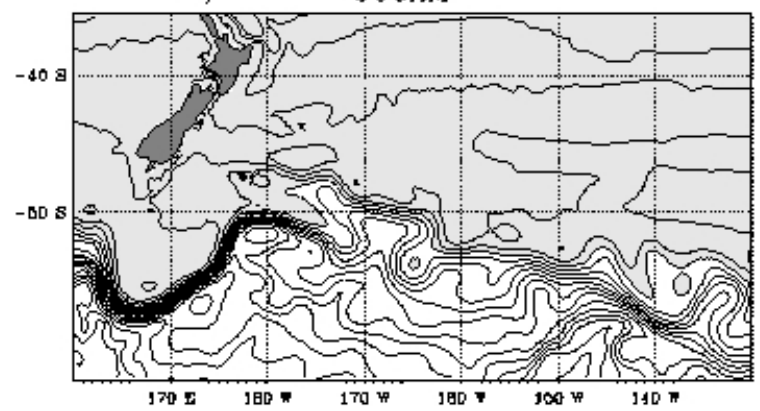

e)

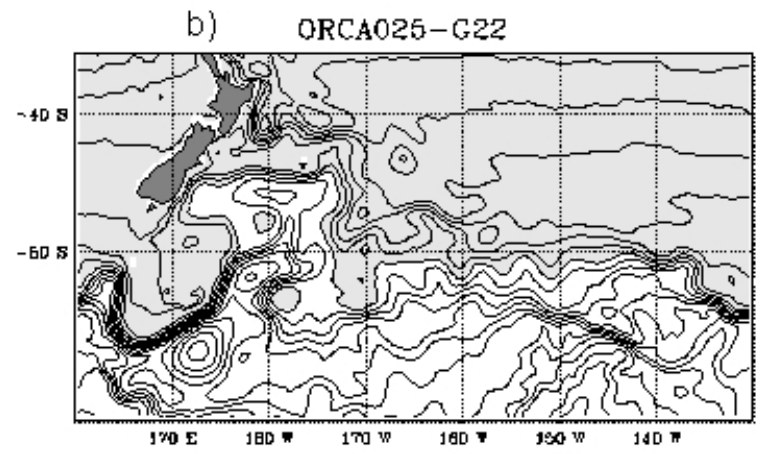

d) ORCA025-G04

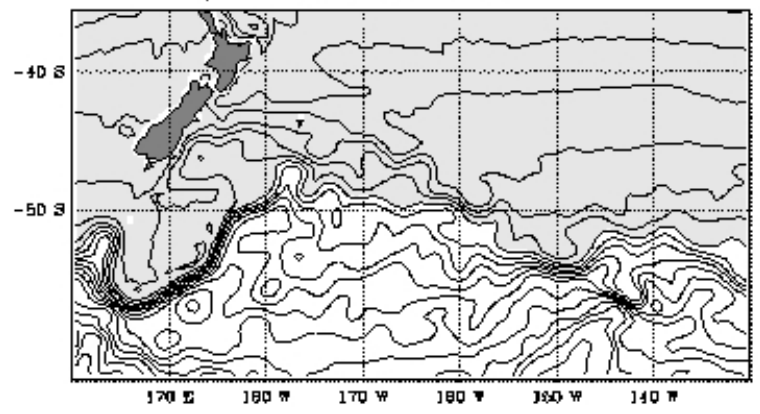

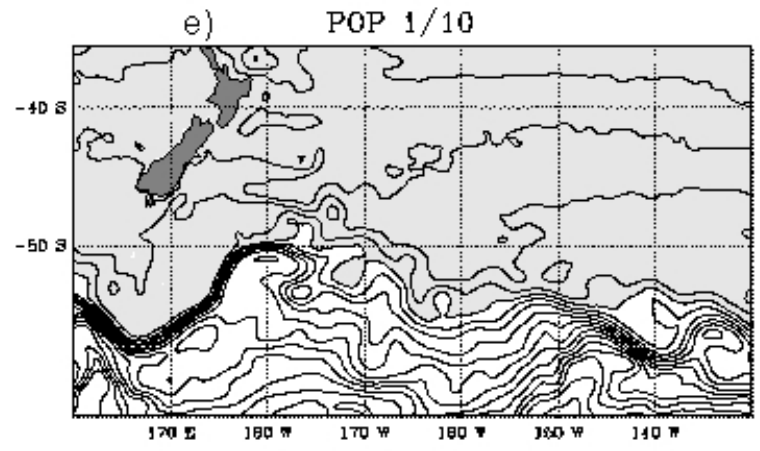

Figure 17: Same as in Fig. 7 (plots of $m s s h$ in $\mathrm{cm}$ ) for the Campbell Plateau in the South Pacific (without the Clipper model which only covers the Atlantic). Contour interval is $10 \mathrm{~cm}$. 


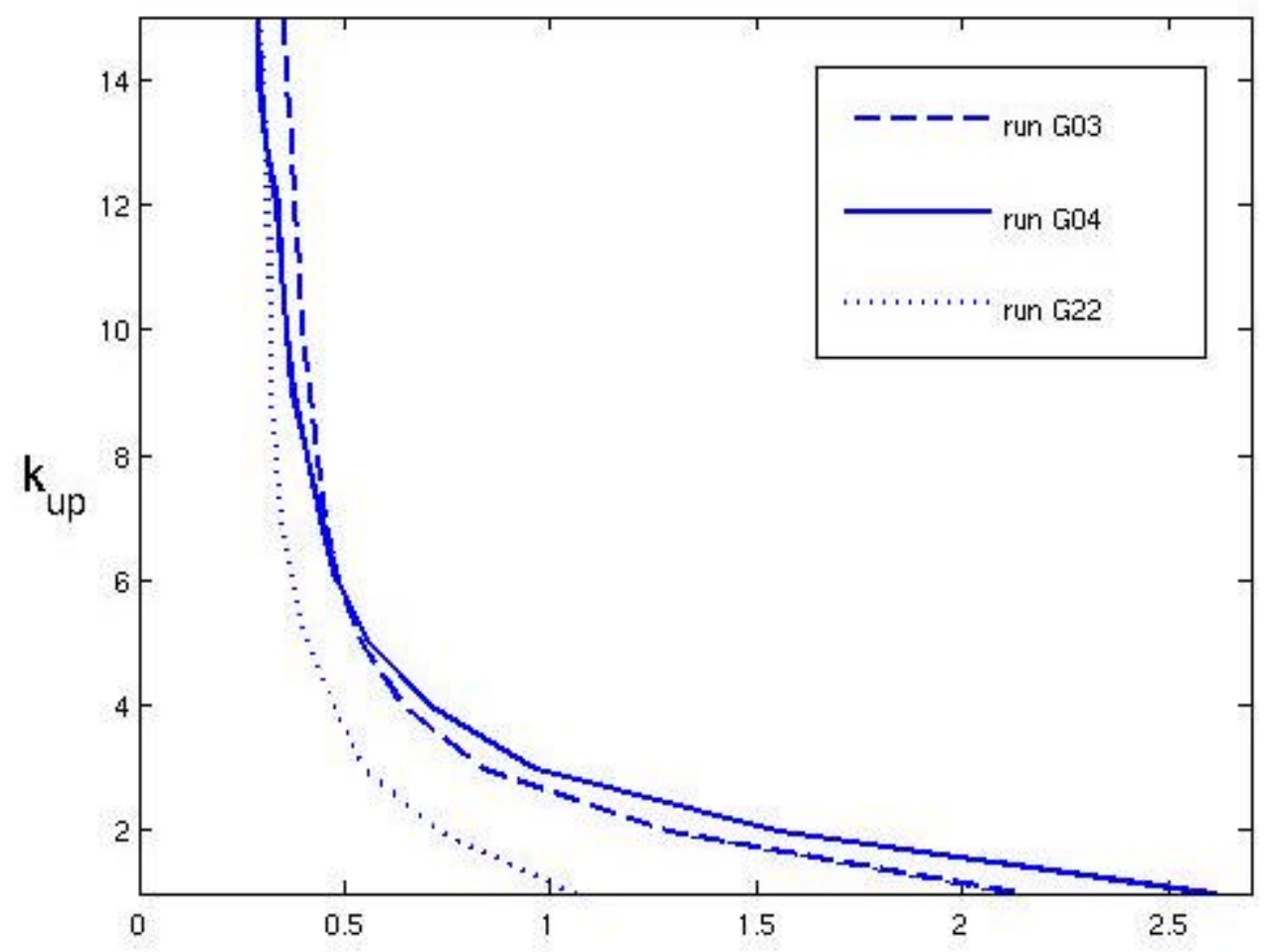

Grid-scale irregularity

Figure 18 : Snapshot of the normalized grid-scale irregularities in vertical velocity fields as a function of the level above the bottom ( $k u p)$, averaged over the Gulf Stream area, in simulations $\mathrm{G} 04(F S+E N S), \mathrm{G} 03(F S+E E N)$, and G22 $(P S+E E N)$. The difference $(\delta w)$ between the vertical velocity $(w)$ and its 9 cell-average $(\bar{w})$ has been computed on each model level. The vertical levels have been re-indexed from the bottom ( $k u p=i$ is the $i^{\text {th }}$ level above the bottom). The gridscale irregularity which is plotted is the ratio between the averages at constant $k u p$ of $|\delta w|$ and $|\bar{w}|$. 